\title{
DNA methylation changes during preimplantation development reveal inter- species differences and reprogramming events at imprinted genes
}

Elena Ivanova ${ }^{1 \dagger}$, Sebastian Canovas ${ }^{2,3+}$, Soledad Garcia-Martínez ${ }^{2}$, Raquel Romar ${ }^{2,3}$, Jordana S. Lopes², Dimitrios Rizos ${ }^{4}$, Maria J. Sanchez-Calabuig ${ }^{4}$, Felix Krueger ${ }^{5}$, Simon Andrews ${ }^{5}$, Fernando Perez-Sanz ${ }^{3}$, Gavin Kelsey ${ }^{1,6^{*}}$ and Pilar Coy ${ }^{2,3^{*}}$ (D)

\begin{abstract}
Preimplantation embryos experience profound resetting of epigenetic information inherited from the gametes. Genome-wide analysis at single-base resolution has shown similarities but also species differences between human and mouse preimplantation embryos in DNA methylation patterns and reprogramming. Here, we have extended such analysis to two key livestock species, the pig and the cow. We generated genome-wide DNA methylation and whole-transcriptome datasets from gametes to blastocysts in both species. In oocytes from both species, a distinctive bimodal methylation landscape is present, with hypermethylated domains prevalent over hypomethylated domains, similar to human, while in the mouse the proportions are reversed.

An oocyte-like pattern of methylation persists in the cleavage stages, albeit with some reduction in methylation level, persisting to blastocysts in cow, while pig blastocysts have a highly hypomethylated landscape. In the pig, there was evidence of transient de novo methylation at the 8-16 cell stages of domains unmethylated in oocytes, revealing a complex dynamic of methylation reprogramming. The methylation datasets were used to identify germline differentially methylated regions (gDMRs) of known imprinted genes and for the basis of detection of novel imprinted loci. Strikingly in the pig, we detected a consistent reduction in gDMR methylation at the 8-16 cell stages, followed by recovery to the blastocyst stage, suggesting an active period of imprint stabilization in preimplantation embryos. Transcriptome analysis revealed absence of expression in oocytes of both species of ZFP57, a key factor in the mouse for gDMR methylation maintenance, but presence of the alternative imprint regulator ZNF445. In conclusion, our study reveals species differences in DNA methylation reprogramming and suggests that porcine or bovine models may be closer to human in key aspects than in the mouse model.
\end{abstract}

Keywords: DNA methylation, Embryo, Epigenetic, Imprinting

\footnotetext{
*Correspondence: gavin.kelsey@babraham.ac.uk; pcoy@um.es

${ }^{\dagger}$ Elena Ivanova and Sebastian Canovas are co-first authors.

1 Epigenetics Programme, The Babraham Institute, Cambridge CB22 3AT, UK

${ }^{2}$ Physiology of Reproduction Group, Departamento de Fisiología, Universidad de Murcia, Campus Mare Nostrum, 30100 Murcia, Spain

Full list of author information is available at the end of the article
}

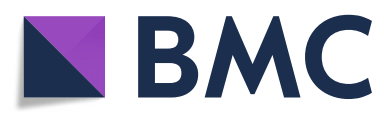

(c) The Author(s). 2020 Open Access This article is licensed under a Creative Commons Attribution 4.0 International License, which permits use, sharing, adaptation, distribution and reproduction in any medium or format, as long as you give appropriate credit to the original author(s) and the source, provide a link to the Creative Commons licence, and indicate if changes were made. The images or other third party material in this article are included in the article's Creative Commons licence, unless indicated otherwise in a credit line to the material. If material is not included in the article's Creative Commons licence and your intended use is not permitted by statutory regulation or exceeds the permitted use, you will need to obtain permission directly from the copyright holder. To view a copy of this licence, visit http://creativecommons.org/licenses/by/4.0/ The Creative Commons Public Domain Dedication waiver (http://creativecommons.org/publicdomain/zero/1.0/) applies to the data made available in this article, unless otherwise stated in a credit line to the data. 


\section{Significance statement}

Our study provides extensive genome-wide datasets that detail at single-base resolution the profound resetting of epigenetic information experienced by gametes and preimplantation embryos. It also provides new insights into establishment and maintenance of DNA methylation imprints. Data are of utmost importance as a reference for species similarity and differences in epigenetic mechanisms occurring during a critical window of development. We consider our study to be of interest to scientists working in developmental biology, evolution, genetics and epigenetics, and also for physicians, patients using ART and researchers seeking to understand how the environment during preimplantation development may have consequences on the epigenome, with further effects after birth and during adulthood.

\section{Introduction}

Genes are inherited from parents and, once their specific sequence after recombination during meiosis is established, they remain almost unaltered through cell divisions during an individual's life, unless external agents or replication mistakes act on them producing mutations. However, changes in epigenetic information, associated with states of gene activity, are at least one order of magnitude more frequent than genetic changes [3] and more susceptible to environmental conditions. Epigenetic states are particularly dynamic during gametogenesis and early embryonic development when extensive reprogramming takes place [7]. Thus, their correct establishment during preimplantation development may be crucial to avoid immediate or future alterations in the offspring's health. According to the DOHAD hypothesis [1], the knowledge of the epigenetic marks that are rewritten during early embryonic development of an individual may serve to predict predisposition to certain diseases in adult life. Therefore, it is important to establish the normal patterns, as well as the expected changes during the lifecourse, of these marks in each species, and find out the similarities and differences between them.

The first genome-scale DNA methylation maps of early embryo development were described over 7 years ago in the mouse $[32,63,66]$, providing a nucleotideresolution view of the unique regulatory wave of global demethylation that had previously been observed by immunofluorescence [59]. Similar principles were subsequently found in human embryos [22, 65]. These and other studies reveal, for example, the distinctive DNA methylation landscape of the mouse and human oocyte, comprising alternating hyper- and hypomethylated domains and predominant gene-body methylation [32, 44, 72]. However, a recent single-cell study has suggested that methylation reprogramming in the cleavage embryo could be more dynamic than previously thought, with remethylation and demethylation events coexisting and affecting different genomic regions during preimplantation development [77].

It has been generally assumed that imprinted genes, which are differentially methylated in the sperm and oocyte, represent an exception to the genome-wide reprogramming events and maintain their methylation marks during preimplantation stages. This persistence of monoallelic methylation is key to ensuring robust monoallelic expression of these genes and the normal development of the embryo $[26,34,53,66]$. However, it has not been fully addressed whether this methylation maintenance is a consequence of a complete lack of reprogramming of these genes or whether they are also affected by demethylation and remethylation waves but are rapidly subjected to imprinting stabilization. Similarly, the identification of germline differentially methylated regions (gDMRs) in different species that maintain their methylation levels through these first cleavage divisions would be crucial to understand the molecular basis of preimplantation development and, consequently, to improve the efficiency and safety of the reproductive processes, especially when assisted reproductive technologies (ART) are used.

In order to describe the methylation landscape of preimplantation embryonic development with a multispecies approach, and determine common and divergent patterns, genome-scale, single-base resolution DNA methylation data were obtained from oocytes, spermatozoa, 2-4 cell embryos, 8-16 cell embryos, morulae and blastocysts of two major livestock species (porcine Sus scrofa and bovine Bos taurus). Datasets from previously published studies on human and mouse were used for comparison. In addition, transcriptome analysis by RNA-seq was performed on porcine and bovine samples collected at the same timepoints to assess correlations with promoter methylation.

\section{Results}

Global DNA methylation dynamics in early porcine and bovine embryos and comparison with mouse and human

In order to characterise the genome-wide patterns of DNA methylation during pre-implantation development in two major livestock species-cow and pig-we generated post-bisulfite adaptor tagging (PBAT) DNA libraries from spermatozoa, oocytes, 2-4 cell cleavage stage embryos, 8-16 cell cleavage stage embryos, morulae and blastocysts (day 6.5-7) from both species. The sequencing output of all libraries (including inferred bisulfite conversion rates) is given in Supplementary Table 1a,b. Replicates within groups were clustered together on the PCA plot (Supplementary Figure 1). After merging the replicates by stage, $\mathrm{CpG}$ coverage rates ranged from 61 to $87 \%$ of CpGs with $>1$ read, and $4-30 \%$ of CpGs with $>5$ reads in the PBAT libraries (Supplementary Figure 2) in pig; for the merged scPBAT dataset from bovine 
oocytes, $61 \%$ of genomic CpGs were represented, and CpG coverage from other stages ranged from 62 to $85 \%$ of $\mathrm{CpG}$ with $>1 \mathrm{read}$, and $2-42 \%$ of CpGs with $>5$ reads (Supplementary Figure 2). Most downstream analysis was performed over features such as $100-\mathrm{CpG}$ windows, and not at individual $\mathrm{CpGs}$, to enable us to aggregate sufficient methylation calls to accurately quantify methylation across these features.

Global methylation levels exhibited similar trajectories from the gametes to the blastocyst in the two species, and these patterns were grossly similar to what has been described in mouse and human preimplantation embryos
[22, 32, 44, 65], but quantitative differences were readily apparent (Fig. 1a). In all species, sperm are highly methylated, and oocytes have an intermediate methylation level. The reduced global methylation at the 2-4 cell stages compared with sperm is consistent with substantial demethylation after fertilisation. Across the cleavage stages, methylation is generally stable but with different absolute levels in the four species; e.g., $54.6 \%$ methylation at the 8 16 cell stages in the pig contrasting with a much lower level in the mouse at this stage (28.0\%). In human, a peak in methylation level at the 8-cell stage has been taken as evidence for ongoing de novo methylation [77]. This is

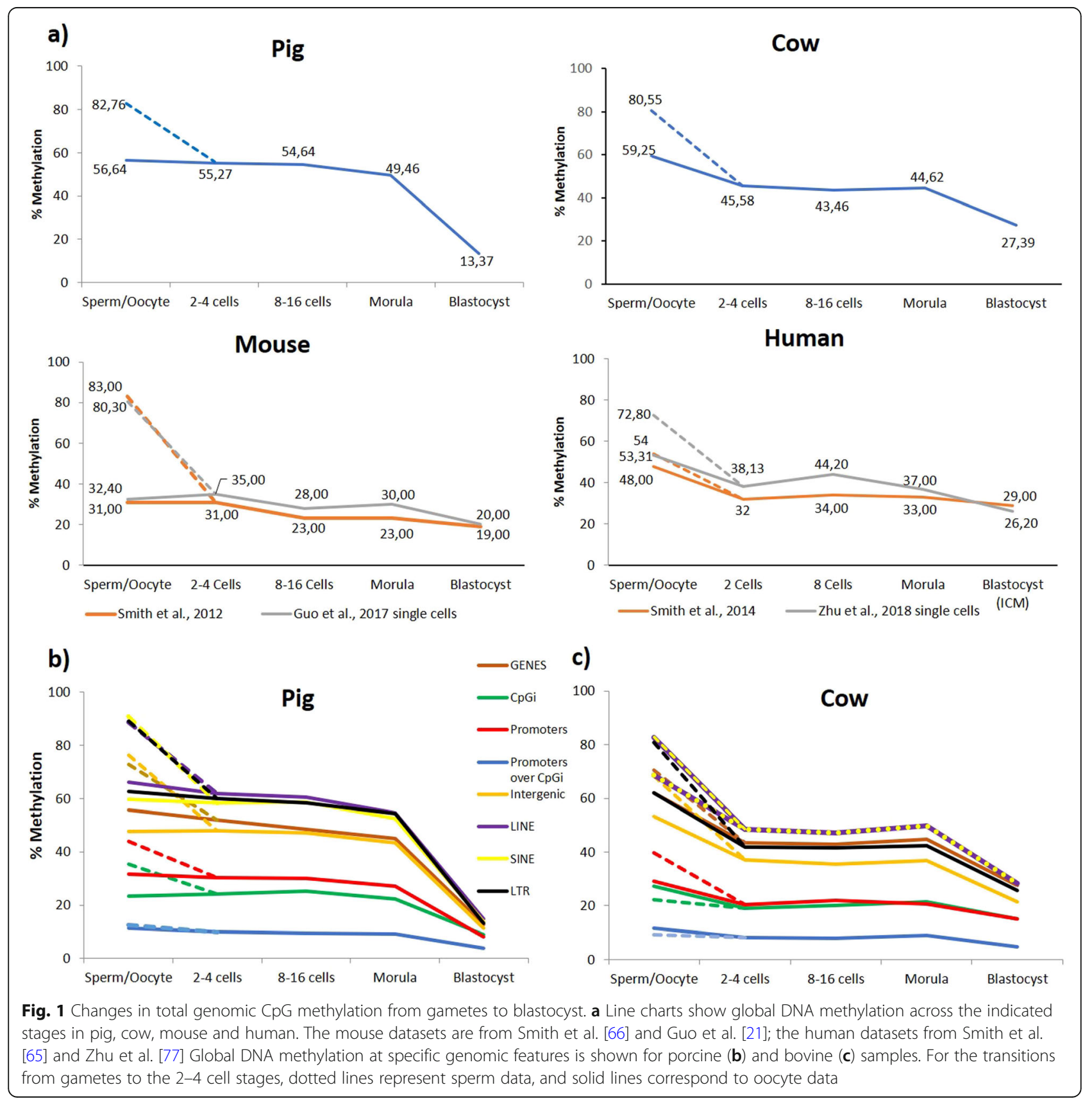


not seen in global methylation either in cow or pig, but below we show evidence for de novo methylation in pig. In all species, methylation is lowest at the blastocyst stage, with the pig showing the most precipitate decline between morula and blastocyst stages (49.5\% to $13.4 \%$ ). When segregating the genome into specific annotations, it is clear that all genomic features follow similar trends, although their averaged methylation levels vary markedly. In both species, promoter $\mathrm{CpG}$ islands consistently have the lowest methylation, while interspersed repeats (SINEs and LINEs) have the highest (Fig. 1b, c). The general transitions in methylation are also apparent in genome browser views, which reveal the contrast between highly methylated sperm and the mosaic methylation pattern of oocytes (alternating hyper- and hypomethylated domains) and the persistence of an oocyte-like pattern of methylation in the cleavage stages, albeit with some reduction in methylation level. This oocyte-like pattern appears to persist weakly even in cow blastocysts, whereas the genome in pig blastocysts has very low methylation with little apparent structure (Fig. 2a, b; Supplementary Figure 3).

For a more detailed evaluation of methylation dynamics, we defined non-overlapping tiles of $100 \mathrm{CpGs}$ over both genomes, yielding 287679 and 268407 probes in the pig and cow genomes, respectively. Our level of sequence coverage allowed us to quantify methylation levels of over $90 \%$ of these tiles at all stages. Also, inspection of methylation levels of $100-\mathrm{CpG}$ tiles revealed qualitative differences between the two species. In the pig, oocytes have a bimodal distribution of methylation, with the greatest numbers of $100-\mathrm{CpGs}$ tiles in the unmethylated $(0-10 \%)$ or fully-methylated $(80-90 \%, 90-$ $100 \%$ ) fractions, whereas bovine oocytes have a far higher proportion of fully methylated tiles and proportionately more partially methylated (the $10-20 \%, 20-$ $30 \%, 30-40 \%$ and $40-50 \%$ bins; Fig. 2c, d). Conversely, and consistent with the global methylation level, over the cleavage stages pig embryos have a higher proportion of highly methylated tiles (60-70, 70-80\% range) than cow, but strikingly in the pig blastocyst there is a very small fraction of tiles with $>20 \%$ methylation.

\section{Conserved pattern of gene body methylation in pig and cow oocytes}

Because of the apparent persistence of an oocyte-like pattern of methylation in embryos in both species (Fig. 2a, b), we looked in more detail at methylation in oocytes. To do this, we segregated the genomes into domains of hypermethylation (HyperDomains; $\geq 75 \%$ methylation) and hypomethylation (HypoDomains; $\leq 25 \%$ ), using methods
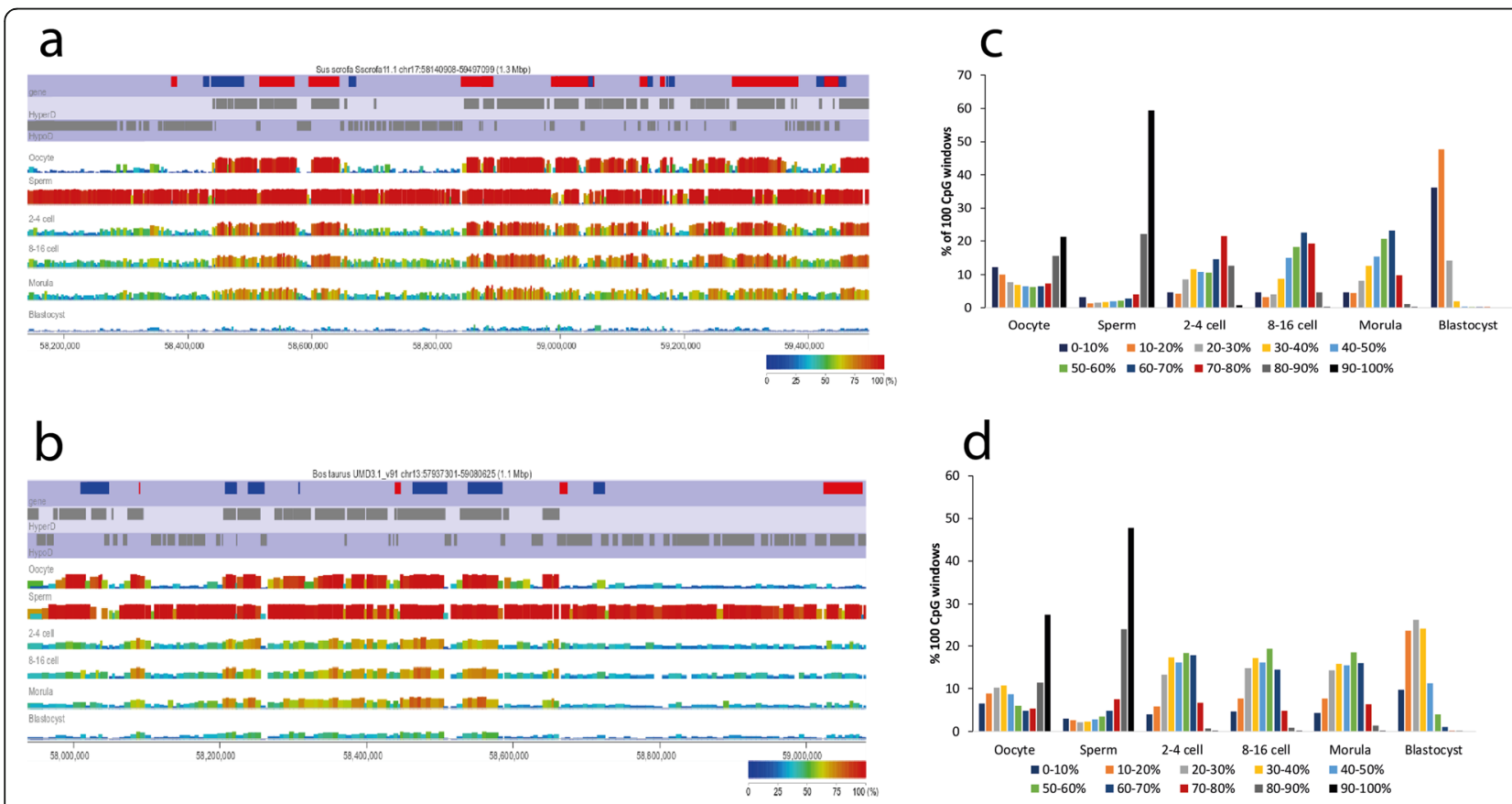

Fig. 2 Changes in the CPG methylation landscape from gametes to blastocyst in pig and cow. Screenshot of Segmonk genome browser at regions of conserved synteny in porcine chromosome 17 (a) and bovine chromosome 13 (b) centred on the GNAS locus. For the profiles for each stage, each vertical bar represents the methylation value of a single, non-overlapping 100-CpG tile, with methylation indicated by the height of the bar and the colour-coding. At the top, the track 'gene' indicates the location of genes, with those marked red being transcribed from left to right, and those marked blue from right to left; HyperDomains (HyperD) and HypoDomains (HypoD) are indicated by bar bars. Histograms of the percentage of $100-\mathrm{CpG}$ windows binned according to the given methylation levels in porcine (c) and bovine (d) samples. The data in $\mathbf{c}$ are based on 253122 informative 100-CpG windows and in $\mathbf{d}$ on 256422 100-CpG windows 
we previously applied in the mouse [72]. This analysis identified 55380 HyperDomains and 54959 HypoDomains in porcine oocytes, which comprise $55 \%$ and $18 \%$ of the queried genome, respectively (Fig. 3a). On average, HyperDomains are larger than HypoDomains (median sizes $13.6 \mathrm{~kb}$ and $6.4 \mathrm{~kb}$, respectively). Bovine oocytes, in contrast, had fewer HyperDomains but a similar proportion of HypoDomains, comprising $46 \%$ and $20 \%$ of the genome, respectively. In comparison, in human the proportion of the genome occupied by HyperDomains and HypoDomains is grossly similar to that of pig and cow with HyperDomains being prevalent over HypoDomains (53\% and 33\%, respectively), while in the mouse the pattern is reversed with HyperDomains occupying only $27 \%$ of the genome and HypoDomains 52\% (Fig. 3a). In both mouse and human, HyperDomains are known to be

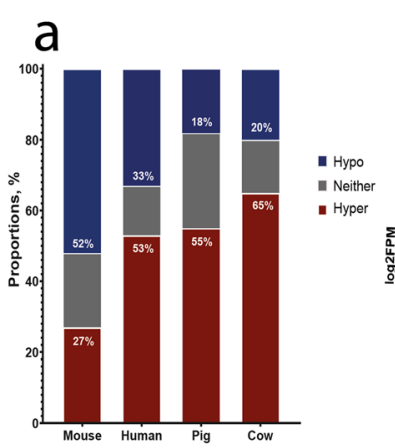

C
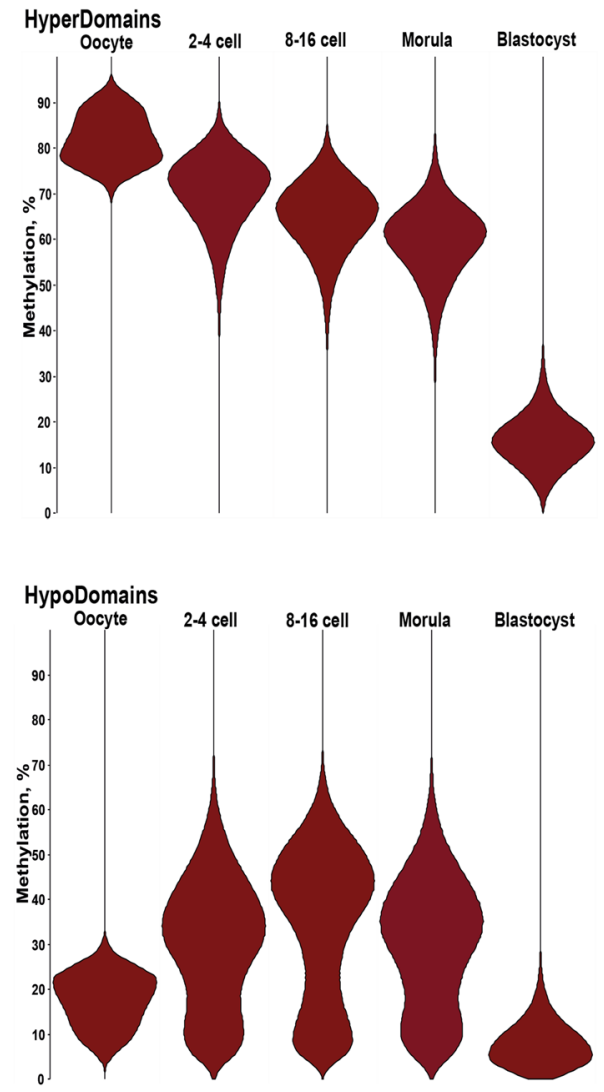

Pig
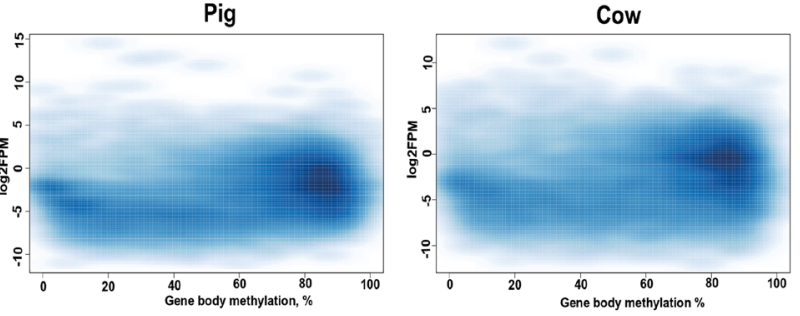

d
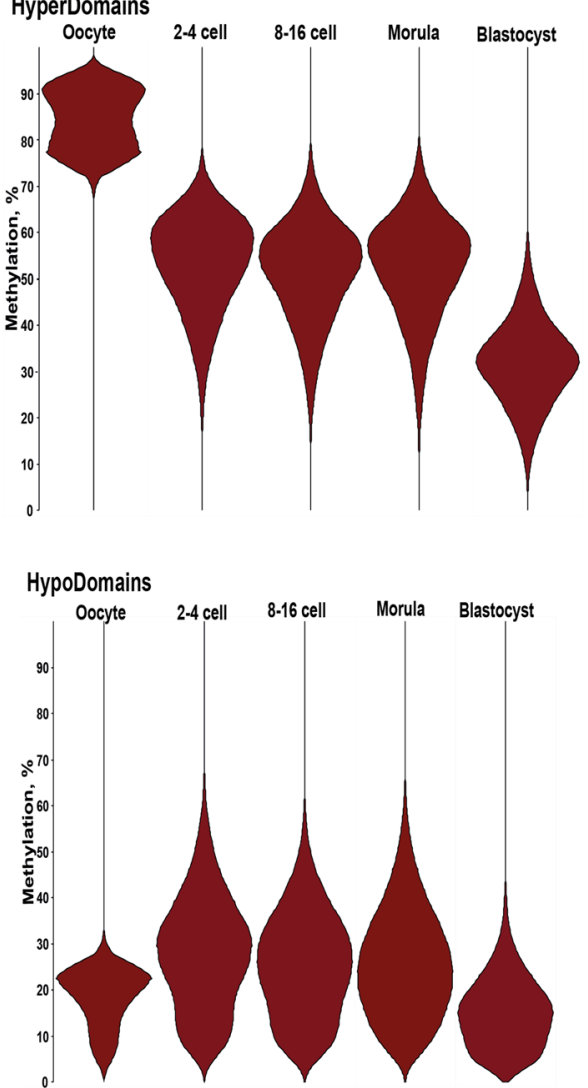

Fig. 3 Properties of hyper- and hypomethylated domains in pig and cow. a Stacked bar chart of the percentage genome coverage of hypermethylated domains (HyperDomains; $\geq 75 \%$ methylation) and hypomethylated (HypoDomains; $\leq 25 \%$ ) in oocytes from pig, cow, mouse and human. b Correlation between gene body methylation and gene expression in pig and cow oocytes. $\mathbf{c}$ Violin plots showing distribution of DNA methylation values (\%) of oocyte HyperDomains and HypoDomains across the indicated stages in pig (c) and cow (d). The data in $\mathbf{c}$ are based on 55380 HyperDomains and 54959 HypoDomains and in d on 40453 HyperDomains and 57969 HypoDomains 
predominantly associated with expressed genes [32, 72]. To test whether this applied also to bovine and porcine oocytes, we evaluated methylation levels of expressed genes from RNA-seq data we obtained from parallel pools of oocytes. Similar to what was previously reported in cow oocytes based on much sparser DNA methylation data [61], genes with high gene body methylation are more likely to be expressed, both in cow and pig (Fig. 3b). Finally, we followed the status of these domains into the preimplantation embryos. Consistent with the globally higher methylation in pig cleavage embryos, the HyperDomains were more highly methylated in pig than bovine embryos (Fig. 3c, d). We note, however, that we are not able to distinguish methylation on oocyte-derived from sperm-derived chromosomes in the embryos, and the fact that these features have a mean methylation of greater than $50 \%$ in pig embryos indicates that the residual methylation is a composite of methylation on maternal and paternal alleles. Interestingly, HyperDomains decline in methylation from the 2-4 cell stages to morula in the pig, indicating continued demethylation, but their methylation is essentially constant in the cow over the same stages (Fig. 3c, d). These findings reveal a more complex dynamic of methylation reprogramming than apparent from the global methylation figures. This complexity is further augmented by the behaviour of the oocyte HypoDomains in cleavage embryos. Specifically in the pig, there is a pronounced increase in methylation at the $8-16$ cell stages (Mann-Whitney, $p<2.2 \mathrm{e}-16$; Fig. 3c). A similar remethylation phase has been observed in human 8 cell embryos, which was found to be associated in particular with young SINEs [77]. To investigate whether there were specific sequence elements associated with regions subject to de novo methylation, we identified all $100-\mathrm{CpGs}$ tiles losing or gaining methylation between the $2-4$ and 8-6 cell stages, filtering for tiles changing by $>10 \%$. In this unbiased approach, we also detected an excess of sites gaining methylation in pig (15.4\%), which was approximately double that in cow (Supplementary Table 3). There was an enrichment for intergenic regions in pig and for gene bodies in cow (Supplementary Figure 4a). Specific regions showing evident gain in methylation at 8-16 cells are shown in Supplementary Figure 4b.

\section{Expression of genes for de novo methylation and demethylation activities}

We investigated the expression and methylation of the genes encoding the major activities involved in DNA methylation reprogramming as a potential explanation for the observed differences in the methylation landscapes between the species (Fig. 4). In general, the expression patterns of transcripts for TET family enzymes in the pig are consistent with previous reports using qRT-PCR, in which TET3 predominates from the oocyte and first cleavage stage with a progressive replacement by TET1 and TET2 [35]; similar observations have been made in mouse [30] embryos. Bovine embryos differed in exhibiting an increase in TET3 transcripts in blastocysts and lack of upregulation of TET2, whereas the dynamics of TET1 expression were consistent with a previous report [46]. Regarding the DNMT family, transcripts for the de novo methyltransferases DNMT3A and DNMT3B as well as the maintenance methyltransferase DNMT1 and its auxiliary protein UHRF1 were readily detected in both pig and cow oocytes. But it was striking that there was no detectable expression of DNMT3L transcripts either in bovine or porcine oocytes or any embryo stage (Fig. 4). DNMT3L is essential as an obligate partner for DNMT3A for de novo methylation in mouse oocytes $[4,62,63]$ but is not expressed in human oocytes [44]. Despite the general maintenance of global methylation levels until the morula in both pig and cow, DNMT1 and UHRF1 transcript levels decline markedly. In the cow, it was notable that DNMT3A and $D N M T 3 B$ transcripts levels recovered very strongly from the morula to blastocyst stage (Fig. 4), which could be associated with the onset of de novo methylation observed in the cow blastocysts [12], although it is not reflected in the global genomic methylation data (Fig. 1).

Several of the TET and DNMT genes are known in the mouse and human to have alternative promoters in oocytes compared with somatic tissues, with their somatic promoters being methylated in oocytes [28, 63]. We were able to identify candidate oocyte-specific and somatic promoters for DNMT1 in both pig and cow. In pig, RNA-seq reads demonstrate that transcripts originating from the candidate oocyte-specific promoter (which we designate DNMT1o) are detected in oocytes and embryos until the morula stage, but transcripts specifically mapping to the annotated, somatic promoter are absent throughout (Fig. 4; Supplementary Figure 5). In pig oocytes, the DNMT1o promoter is unmethylated $(<10 \%)$ and the somatic promoter methylated $(\sim 61 \%)$. In cow, there is evidence for transcripts initiating both from the DNMT1o and somatic promoters in oocytes, which are also detected in 2-4 cell embryos, after which only canonical transcripts are detected (Supplementary Figure 5). Consistent with activity of both promoters, they are both unmethylated $(<20 \%)$ in cow oocytes (Fig. 4$)$. The annotated TET3 promoters were highly methylated in pig and cow oocytes (Fig. 4). In the cow, the marked increase in TET3 transcript abundance at the blastocyst stage occurs despite relative high maintenance of methylation of the somatic promoter, which might indicate activation of the gene in a subpopulation of cells that lack promoter methylation. Similarly, the pronounced upregulation of DNMT3A and DNMT3B transcripts in bovine 


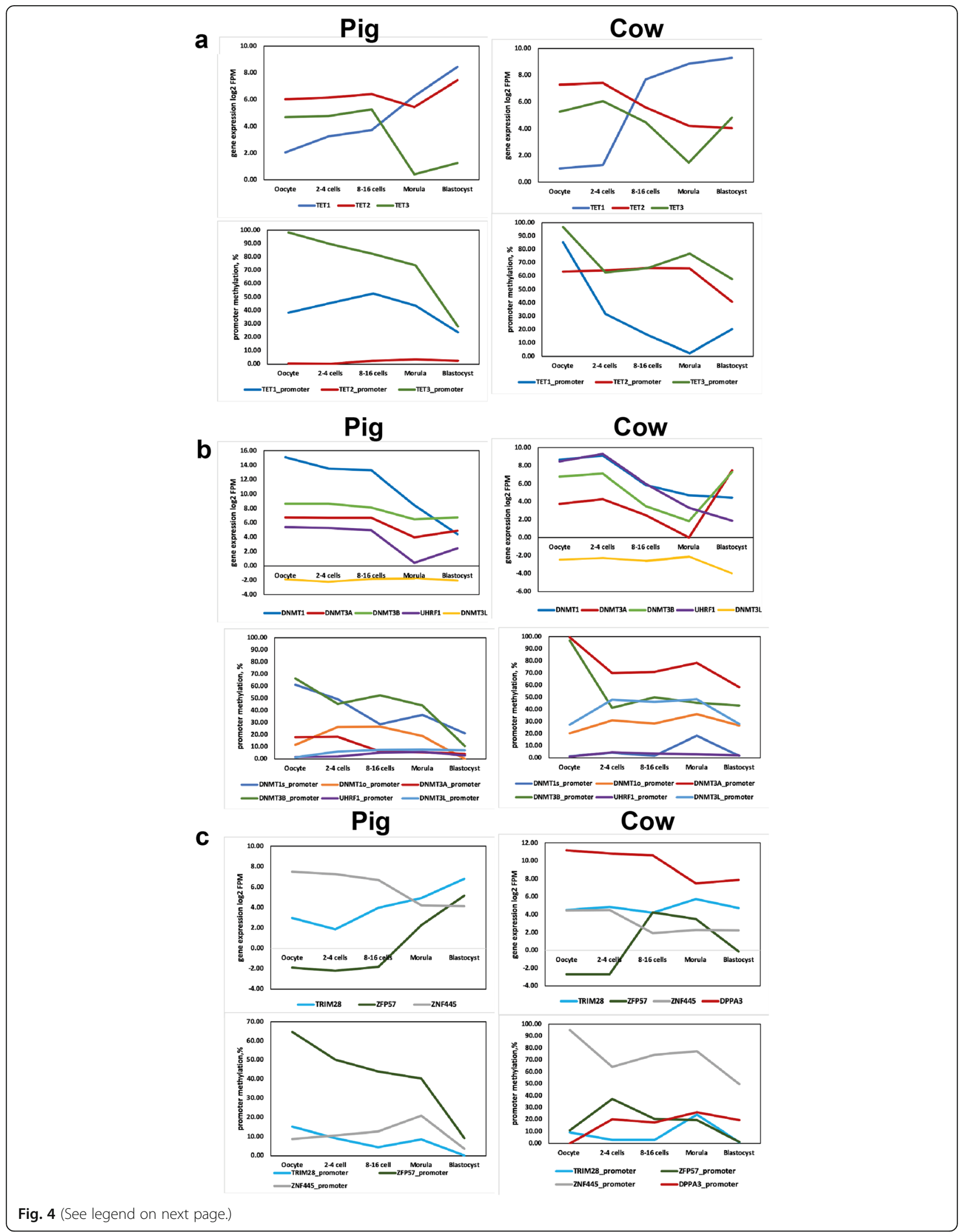


(See figure on previous page.)

Fig. 4 Expression and promoter methylation of genes for de novo methylation and demethylation activities. a TET family enzymes expression and DNA methylation at the promoters. $\mathbf{b}$ DNMTs expression and DNA methylation at the promoters. $\mathbf{c}$ Gene expression and promoter methylation for key factors known to be involved in the mouse and/or human in maintaining DNA methylation at germline differentially methylated regions (gDMRs): the zinc-finger proteins ZFP57, ZNF445, TRIM28 (KAP1) and DPPA3

blastocysts also occurred against relatively high levels of promoter methylation (Fig. 4).

We also evaluated expression and methylation of genes for key factors known to be involved in the mouse and/or human in maintaining DNA methylation at germline differentially methylated regions (gDMRs): the zinc-finger proteins ZFP57 and ZNF445 that have sequence-specific binding for methylated gDMRs and recruit TRIM28 (KAP1), part of the complex that mediates DNA methylation and repressive chromatin [36, 39, 41, 51, 67]. ZFP57 is a maternal effect protein for gDMR maintenance in the mouse but is not expressed in human oocytes. Strikingly, in both pig and cow ZFP57 transcripts were undetectable in oocytes and only appeared at the 8-16 cell or morula stages; in pig, lack of expression was associated with high promoter methylation in oocytes (Fig. 4). In contrast, and similar to the situation in human [67], ZNF445 transcripts were abundant in pig [74] and cow oocytes, suggesting that this protein substitutes for ZFP57 in the initial maintenance of gDMR methylation (Fig. 4). The detection in cow and/or pig oocytes of transcripts for TRIM28 and DPPA3, which in the mouse are maternal effect proteins for DMR maintenance (TRIM28 [41];) or for protecting the maternal genome from active demethylation (DPPA3 [42];), would be compatible with roles of these proteins also in these two species.

\section{Gametic DMRs and candidate imprinted genes in the pig and cow}

We looked in more detail at the gametic methylation patterns as a means of understanding the nature of methylation differences and the potential for specifying imprinted genes. As a first analysis, we assigned $100-C p G s$ tiles as hypermethylated $(\geq 75 \%)$ or hypomethylated $(\leq 25 \%)$ in either gamete. Tiles hypermethylated both in sperm and oocyte generally followed the genome average in both pig and cow in relation to distribution of genomic features such as genes, CGIs and interspersed repeats (Supplementary Figure $6 \mathrm{a}, \mathrm{b})$. The same was true for sperm-specific DMRs, albeit with some enrichment for intergenic regions (Supplementary Figure 6c). In contrast, tiles hypomethylated in both gametes were very strongly enriched in CGIs and promoters, as might be expected (Supplementary Figure 6d). For oocyte-specific DMR tiles, there was also a very strong enrichment in genes and CGIs (Supplementary Figure 6e). Indeed, we identified 700 CGIs specifically methylated in pig oocytes and 1411 methylated in cow oocytes. This is comparable to mouse (1329) and human (1440) oocyte-specific methylated CGIs [32, 44].

Inspection of the oocyte-specific or sperm-specific DMRs that contained CGIs revealed that they included some of the known imprinted genes, as might be anticipated (data not shown). We further filtered the gametic DMRs for tiles that retained intermediate methylation (30-70\%) through to the blastocyst stage as a means of identifying candidate imprinted genes in the pig and cow (Datasets 1 and 2). Imprinted genes have been identified in both species (listed at http://www.geneimprint.com/), but mostly as a result of candidate single gene analysis from known imprinted genes in mouse/human, or by expression analysis in parthenogenetic embryos/blastocysts. In the pig, we identified 160 oocyte-specifically methylated CGIs that retained intermediate methylation in blastocysts (Dataset 1, Maternal imp candidat $\mathrm{CpGi}$ targ); these included nine imprinted genes that matched the list at http://www.geneimprint. $\mathrm{com} /$ or corresponded to imprinted genes in mouse and human (DIRAS, HERC3/NAP1L5, IGF2R, INPP5F, MEST, PEG3, PLAGL1, GNAS and NNAT). When we extended the analysis to any 100-CpGs tile fitting the same criteria (hypermethylated in oocytes, hypomethylated in sperm, intermediately methylated in blastocysts), there were just 183 tiles (Dataset 1, Maternal imp DMR cand Global), of which 25 coincided with imprinted gDMRs known from mouse or human; this analysis added KCNQ1 and PEG10. This relatively high hit rate suggests that the approach is useful for identification of candidate imprinted genes in this species. When applying the same approach to CGIs specifically methylated in sperm, none of the 74 hits (Dataset 1 , Paternal imp candidat CpGi targ) corresponded to an imprinted gene known from other species, but when the filter was relaxed for any 100-CpGs window fitting the methylation criteria, three candidate imprinted genes from the DLK1-DIO3 domain were identified (BEGAIN, MEG3, RTL1) out of 374 tiles (Dataset 1, Paternal imp DMR cand Global). Therefore, for imprinted genes specifically methylated in sperm, the approach appears less successful. We used the same logic in the cow methylation datasets. Focusing on CGIs specifically methylated in oocytes, 88 met the criteria (Dataset 2, Maternal Imprint Cand CpGi targ), of which MEST, SGCE and SNRPN are known to be imprinted. When all 100-CpGs tiles were considered irrespective of overlap with CGIs, 1048 tiles met the criteria (Dataset 2, Maternal Imp DMR Cand Global), which included the genes ASB4, BLCAP, B4GALNT4, GNASL, HERC3, MEST, MZF1, PEG10, TRAPPC9, SIM2 and 
SNRPN (representing seventeen 100-CpGs tiles or 1.52\%). Therefore, it seems that the approach may be less specific in the cow, with a likely higher rate of false positives. When assessing CGIs specifically methylated in sperm, 42 were found to be intermediately methylated in blastocysts including a CGI at IGF2 (Dataset 2, Paternal Imprint Cand CpGi targ). When all 100-CpGs windows were considered, 4004 met the criteria, including at BEGAIN, IGF2, INS, RASGRF1 and RTL1 (Dataset 2, Paternal Imp DMR cand Global), but the larger number of 'hits' suggests a high rate of false positives again. It is likely that the gross difference in DNA methylation levels in cow compared with pig blastocysts contributes to this apparently low specificity: with a global level of methylation of $27 \%$ in blastocysts in the cow, any imprecision in methylation level estimates from the PBAT data could place non-imprinted features into the candidate imprinted category at an inclusion threshold of $\geq$ $30 \%$. As a first step towards validating the gDMRs as elements regulating potential new imprinted genes, we assessed the locations of these gDMRs in relation to genes found to be monoallelically expressed by RNA-seq analysis of placenta and fetal tissues from of a Bos taurus taurus $\mathrm{x}$ B. t. indicus cross [9]. Of the 45 autosomal imprinted transcripts reported by Chen et al., our DMR candidates mapped within or close to $(<50 \mathrm{~kb}) 15$ known imprinted genes and close to 7 novel imprinted genes (Supplementary Table 4).

With a list of candidate imprinted gDMRs, including from confirmed imprinted genes and those with homology to human or mouse imprinted loci indicated above, we then evaluated their methylation dynamics in preimplantation embryos. For the maternally methylated gDMRs in pig, methylation levels at the 8-16 cell stages were significantly reduced compared with the 2-4 cell stages (Fig. 5a). Thereafter, two patterns were apparent, with gDMRs such as IGF2R, DIRAS3, PEG3 and MEST gaining methylation to an expected $\sim 50 \%$ by morula and maintaining this level in the blastocyst, whereas for gDMRs like NNAT, PLAGL1 and NAP1L5 restoration of $\sim 50 \%$ methylation occurred only in the blastocyst (Fig. 5a). These patterns suggest complex remodeling of gDMR methylation over this time, which could be compatible with differences in the requirement for and timing of expression of methylation maintenance factors, such as ZFP57 or ZNF445 (Fig. 4). In bovine preimplantation embryos, in contrast, there was no consistent reduction in methylation at the 8-16 cell stages and greater apparent stability of maternal gDMR maintenance (Fig. 5b).

\section{Correlations between expression and promoter methylation for pluripotency and ZGA genes and hypermethylated gamete promoters}

Given the prominent role during early embryo development of pluripotency genes and those related with the zygote genome activation (ZGA), we performed correlation analysis between gene expression and methylation at the promoters of these genes in our datasets. Here, again, there were some notable differences between the pig and cow. In the pig, ZGA gene promoters were relatively highly methylated in oocytes, and methylation state in oocytes showed a weak positive correlation with expression that persisted across at all embryonic stages (0.33 at the 2-4 cell stages to 0.25 in blastocysts; Supplementary Figure 7). Similar weak positive correlations were observed between methylation and expression within all stages, declining in the blastocyst. In contrast, ZGA gene promoters showed a bimodal range of methylation in cow oocytes and a complete absence of correlation between oocyte methylation and expression in cleavage embryos, or tending towards a negative correlation (Supplementary Figure 8). These general trends applied also to the smaller set of pluripotency genes (Supplementary Figure 7 and 8). Finally, we studied the gene expression dynamics following fertilisation for hypermethylated sperm and oocyte promoters that are demethylated more than $50 \%$ by the cleavage stage, as Smith et al. did with human data [65]. We did not find a significant difference in the number of demethylated gamete promoters that exhibited up or downregulation (> two-fold) in expression compared to other promoters.

\section{Discussion}

The results of this study detail the DNA methylation dynamics during the first week of development in two major livestock species where this information was not previously available: Sus scrofa and Bos taurus. In both species, a partial picture of these events can be inferred from immunostaining data $[8,14]$. More recently, reduced representation bisulfite sequencing (RRBS) [31] and single-cell genome-wide profiling [15] until the morula stage have been applied, albeit with lower $\mathrm{CpG}$ coverage, in the cow, but neither provide a comprehensive, genome-wide characterization of DNA methylation at the single-base level or accurate estimates of global methylation until the blastocyst stage. When comparing our results in cow and pig to those of human and mouse, we observed that the cow followed a similar pattern of demethylation from the oocyte to the 2-4 cell stages as human; however, this was not the case for pig, which is similar to mouse [21, 66]. The delay of active conversion of 5-methylcytosine $(5 \mathrm{mC})$ in the maternal genome to 5 -hydroxymethylcytosine $(5 \mathrm{hmC})$ by TET3 has been explained in mouse studies by protection of the oocyte genome by STELLA/PGC7/DPPA3 [42], but the direct lack of demethylation had not been considered until now. We hypothesize that differences in the transition from maternal control of development to zygotic control, occurring at different timepoints depending on the species 

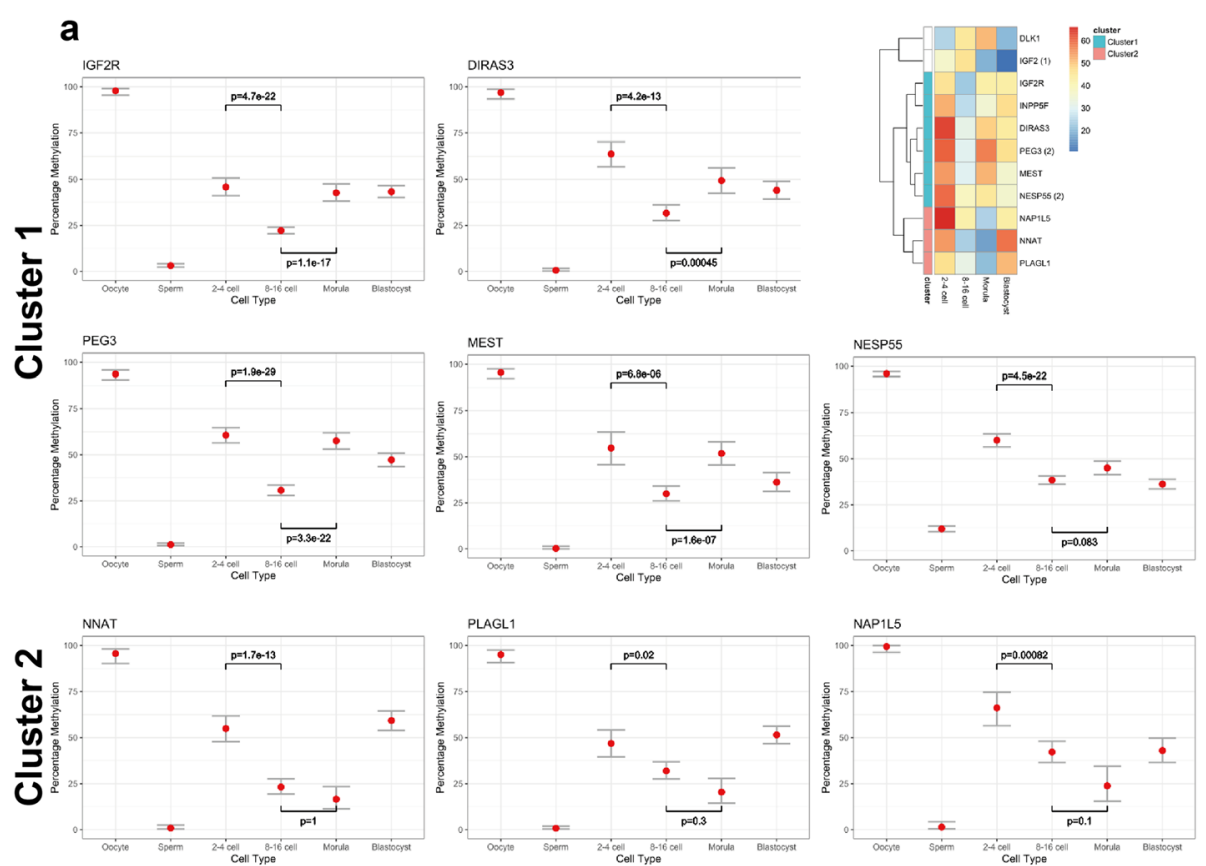

b

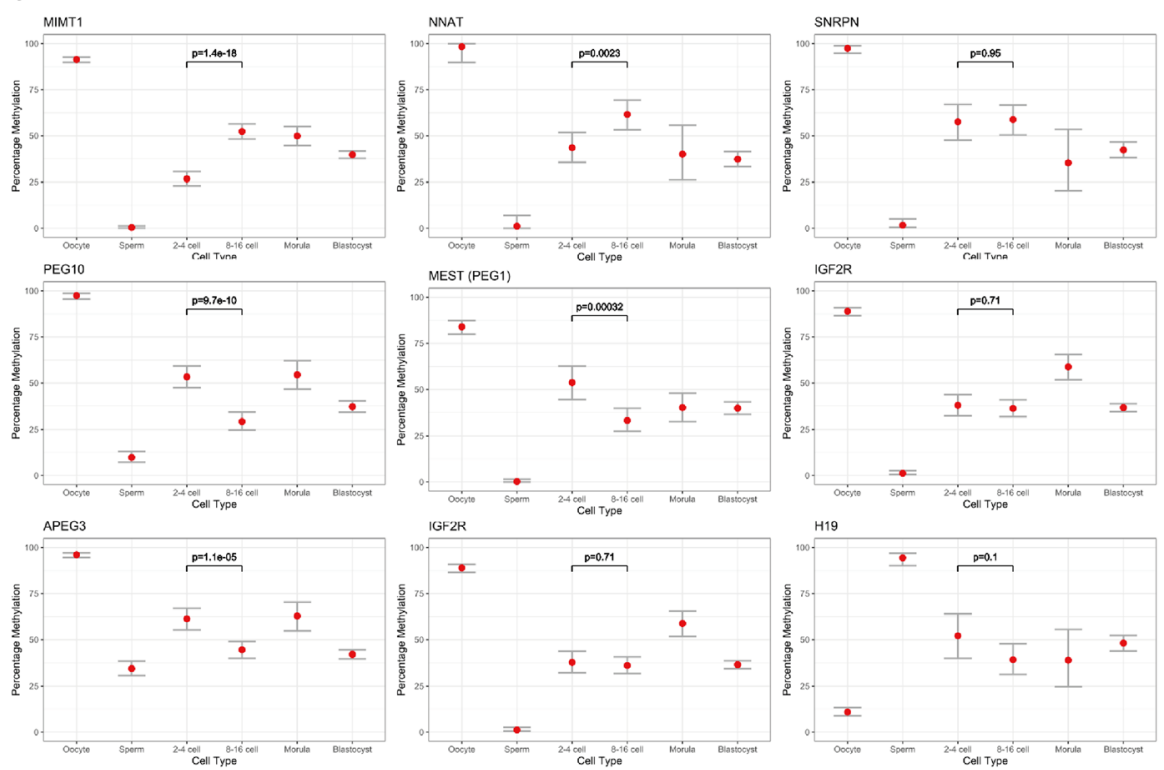

Fig. 5 DNA methylation dynamics of candidate imprinted genes in the pig (a) and cow (b). In pig, two clusters were identified based on the time of remethylation ( 50\%): morula stage for cluster 1 and at the blastocyst stage for cluster 2

and connected with the pluripotency programme, could help to explain this finding. Indeed, it is accepted that in human and monkey, the major ZGA wave takes place during the $4-8$ cell stages $[60,71,73]$, while in the cow this happens later, at the $8-16$ cell stages [68], but earlier in the pig and mouse ( 2 cell stages in mouse and 4 cell stages in pig) $[29,68,75]$. Therefore, the fact that ZGA in the pig and mouse occurs earlier in development could support our hypothesis. Conversely, the male genome is rapidly demethylated in both cow and pig, and this finding has also been well described in other species [21, 31, 77]. We did not observe global re-methylation peaks either in pig or cow, as described by Jiang et al. in cow [31], Zhu et al. in human [77] and Guo et al. in mouse [21]. These discrepancies could be explained by technical differences in the methods used in relation to the sequences covered (i.e., RRBS vs whole genome bisulfite sequencing). But we also found that a transient remethylation phase was detectable in pig embryos specifically of sequences hypomethylated in oocytes. These locus-specific fluctuations 
occurred in the presence of relatively constant levels of Dnmt $3 A / 3 B$ transcripts during first cleavage divisions. The dynamics of DNMT expression in oocytes and early embryos have been characterised in mouse, bovine, rhesus monkey and humans and shown to exhibit differences between species (reviewed by [70]). We detected progressive reduction in expression and promoter methylation of DNMT1 in the pig from the oocyte to the blastocyst stage. The observed decrease in DNMT1 transcripts could represent the degradation of oocyte-derived mRNA. In our RNA-seq data, we detected an additional DNMT1 transcript with a transcriptional start site upstream of the canonical promoter in both pig and cow oocytes; this could represent DNMT1o, an oocyte-specific transcript earlier described in human [24] and mouse [40], but its existence in cow has been considered unlikely [56]. From RNA-seq data, it appears that DNMT1 transcripts identified in the oocyte and early embryo in pig originated from this alternative promoter, after which DNMT1 was expressed from the somatic promoter. In the cow, in contrast, both DNMT1o and somatic-form transcripts were present in the oocyte and 2-4 cell embryos, indicating a striking difference in the regulation between the species. The switch from the oocyte to somatic isoforms may be important for sub-cellular localisation of the corresponding proteins. In cow, as in the mouse, DNMT1 is found in the cytoplasm in zygotes but not in 8-16 cell embryos where it was mostly nuclear [37]. The switch to somatic form of DNMT1 in cow at 8-16 cell stages could be important before de novo methylation by DNMT3A and DNMT3B initiates at the blastocyst stage. DNMT3A and DNMT3B showed a significant increase in expression from the morula to the blastocyst stage in the cow; there was no comparable increase in the pig. In previous studies, it was suggested that de novo methylation in the cow starts from the 8-16 cell stages [12]. This could account for why the methylation level observed at the blastocyst stage in the cow (around 27\%) did not drop to values as low as those observed in the pig (around 13\%). In comparison, results from immunostaining in the pig indicated that methylation reaches a minimum at the late blastocyst stage [13] and, according to our RNA-seq data, DNMT3A and DNMT3B expression remained low at this time. Low levels of DNMT3A and DNMT3B in pig blastocysts have also been observed by others [76]. We suggest that unlike cow, de novo methylation does not start until later embryonic stages in pig, possibly until blastocyst expansion. The increasing expression of TET1 and TET2 enzymes through these first days of development shown in our data could also explain the extremely low levels of methylation in pig blastocysts. High levels of TET3 transcripts in both cow and pig from oocyte to the 8-16 cell stages likely reflect its role in active demethylation of the paternal genome, as has been proposed from extensive mouse studies
[25]. However, the gene expression profile and promoter methylation of components of the DNA methylation machinery cannot fully explain the variation in global methylation landscape or in imprinted gene reprogramming amongst the species. It is possible that other epigenetic mechanisms, such as post-translational modifications, are involved in the process of gene expression regulation, acting specifically at promoters devoid of CGIs, for example H3K9me2/3 marking inactive heterochromatin in CGIpoor promoters [2].

It is generally accepted, from murine and human data, that DNA methylation marks at the DMRs of imprinted genes are established in the parental germline and robustly maintained through early development, by the action of a complex set of factors including DNMT1, ZFP57 and/or ZNF445 and KAP1/TRIM28 [10, 26, 33, 66]. However, our data suggest a greater dynamic of gDMR methylation, and few appear to maintain the expected 50\% methylation from the 2-4 cell stages to blastocyst stage; moreover, different patterns were apparent amongst gDMRs, particularly in pig. These results are compatible with previous suggestions [43] that DNA methylation status of imprinted gene DMRs during the first days of development might be variable and could require an active period of imprint stabilization until the blastocyst stage [69]. It is possible that the differences in methylation dynamics of various gDMRs reflect differences in dependence on factors such as ZFP57 and ZNF445 in methylation maintenance [67], and our observation that the transcripts for these two factors have distinct expression patterns from the oocyte to blastocyst in both species may be important in this context.

We used our methylation datasets to identify CGIs (or $100-\mathrm{CpG}$ windows) that have gametic and embryo methylation patterns consistent with parent-of-origin monoallelic methylation as a means towards discovering potential new imprinted sequences, as has been done in other species [32, 44]. This approach appears more promising in pig than in cow, judging by the greater proportion of known imprinted genes amongst the candidates DMRs in pig and the much higher number of candidates in cow, probably on account of the higher genome-wide methylation in cow blastocysts. Nevertheless, 7 of our candidates mapped close to novel imprinted transcripts identified in a recent study that employed RNA-seq in fetal bovine tissues [9] . It should be noted that monoallelic methylation in the blastocyst is not a guarantee of persistence of imprinting at later stages, as many CGIs that retain parentof-origin methylation in mouse blastocysts become biallelically methylated or biallelically unmethylated post implantation, a phenomenon termed 'transient imprinting' [49]. This is not to say that transient imprints are inconsequential, as long-lasting imprinted expression states can be set up with physiological significance although the 
initiating methylation mark is lost, as in the case of the mouse $Z d b f 2$ locus [16, 20]. In addition, in human, there is a greater persistence of DMRs in the placenta than embryo proper $[23,58]$, which might indicate a greater role for non-classical imprinted genes in this tissue. The full significance of gametic methylation beyond classical imprinted genes remains to be elucidated.

In terms of the functions of imprinted genes, both PEG10 and NNAT proteins are highly expressed in placenta and play crucial roles during early development, being associated with normal formation of the placenta itself [45] (PEG10) and to the formation of nervous system $\mathrm{Ca}^{2+}$ signalling, glucose transport, insulin secretion and inflammation [48] (NNAT). Transcripts from GNAS complex locus, on the other side, are involved in different signal transduction pathways and a variety of cellular responses, having being also associated with intrauterine growth retardation and thus small size for gestational age [54]. The precise physiological significance of these observations remains to be further investigated.

It should be noted that the embryos analysed in this study were obtained after in vitro maturation of oocytes, in vitro fertilisation and embryo culture. The potential for these manipulations and culture media to impair normal DNA methylation events in oocytes and maintenance in cleavage embryos has been much discussed $[5-7,74]$. At this time, it appears that interventions required to obtain mature oocytes have limited impact on the establishment of normal DNA methylation patterns in oocytes themselves (e.g., [57]), but there is more evidence that they, or embryo culture, can lead to some compromise in methylation reprogramming or maintenance of imprinted methylation in preimplantation embryos $[5-7,9,17,18]$. Therefore, the methylation patterns of purely in vivo derived gametes and embryos could differ in some details from the results presented here. Similarly, it should be noted that porcine oocytes were obtained from prepubertal rather than adult sows. In the mouse, it has been described that although the DNA methylation patterns are highly similar, there are a limited number of discrete DNA methylation differences in oocytes collected from immature compared with mature females [57]; a similar effect could apply in pig.

In conclusion, we provide a detailed comparative evaluation of the DNA methylation patterns of oocyte and sperm, and the post-fertilisation dynamics of methylation, in the cow and pig. Our results indicate differences between these two major livestock species, and differences in several respects from the pattern observed in mouse, which has been the model organism of choice to now. These differences extend to the timing and extent of methylation reprogramming and the expression pattern of the key methylation and demethylation activities. Moreover, our data support the hypothesis we previously suggested [5-7] about a general uncoupling between DNA methylation and gene expression during demethylation of gametes at preimplantation development. This also applies to imprinted genes. In many respects, the expression patterns of DNMTs as well as the zinc-finger proteins ZFP57 and ZNF445 critical for maintenance of DNA methylation at imprinted genes in these species mirror those of human gametes and embryos more closely than the mouse, suggesting that they could provide a more faithful model for human for the regulation of epigenetic reprogramming. These data also provide a valuable reference against which to assess the epigenetic fidelity of ART.

\section{Materials and methods \\ Collection of gametes and embryo samples In vitro maturation (IVM) for collection of pig oocyte samples}

The in vitro maturation (IVM) was performed as previously described [11]. Briefly, within $30 \mathrm{~min}$ of slaughter, ovaries from pre-pubertal Landrace-Large-White gilts were transported to the laboratory in saline containing $100 \mathrm{mg} \mathrm{mL}^{-1}$ kanamycin sulphate at $38{ }^{\circ} \mathrm{C}$, washed once in $0.04 \%$ cetrimide solution and then twice in saline. Cumulus celloocyte complexes (COCs) were collected by aspiration from antral follicles (3 to $6 \mathrm{~mm}$ diameter), washed twice with Dulbecco's PBS supplemented with $1 \mathrm{mg} \mathrm{mL}^{-1}$ PVA, then washed twice more in maturation medium previously equilibrated for a minimum of $3 \mathrm{~h}$ at $38.5{ }^{\circ} \mathrm{C}$ under $5 \% \mathrm{CO}_{2}$ in air. Maturation medium NCSU-37 [47] supplemented with $0.57 \mathrm{mM}$ cysteine, $1 \mathrm{mM}$ dibutyryl cAMP, $5 \mathrm{mg} \mathrm{mL}^{-1}$ insulin, $50 \mathrm{mM} \beta$-mercaptoethanol, $10 \mathrm{IU} \mathrm{mL}^{-1}$ equine chorionic gonadotropin (eCG; Folligon; Intervet International BV, Boxmeer, Holland), $10 \mathrm{IU} / \mathrm{mL}$ hCG (VeterinCorion; DivasaFarmavic, Barcelona, Spain) and 10\% porcine follicular fluid (v/v) was used.

Groups of 50-55 COCs with complete and dense cumulus oophorus were cultured in $500 \mu \mathrm{L}$ maturation medium for $22 \mathrm{~h}$ at $38.5{ }^{\circ} \mathrm{C}$ and $5 \% \mathrm{CO}_{2}$ in air saturated of humidity. After culture, COCs were washed twice in fresh maturation medium without dibutyryl cAMP, eCG and hCG and cultured for an additional 20-22 h [19].

\section{In vitro fertilisation (IVF) and embryo culture (EC) for collection of pig embryo samples}

After $42-44 \mathrm{~h}$ of maturation, cumulus cells were removed by pipetting, and groups of 45 to 50 denuded oocytes were transferred into each well of a 4-well multidish containing $250 \mu \mathrm{L}$ TALP medium [52] previously equilibrated at $38.5{ }^{\circ} \mathrm{C}$ under $5 \% \mathrm{CO}_{2}$ in air. Semen samples were collected by the gloved hand method from fertility-tested boars (1-2 years old) and immediately transported to the laboratory. Sperm were processed by the swim-up method using NaturARTs ${ }^{\circ}$ 
PIG sperm swim-up medium (Embryocloud, Murcia, Spain) as previously described [5-7]. Briefly, the swimup medium was supplemented with bovine serum albumin $3 \mathrm{mg} / \mathrm{mL}$ (BSA-FAF), and $1 \mathrm{~mL}$ of ejaculated spermatozoa was lay below $1 \mathrm{~mL}$ of NaturARTs ${ }^{\oplus}$ PIG sperm swim-up medium at the bottom of a conical tube. After 20 min of incubation at $37{ }^{\circ} \mathrm{C}$ (with the tube at a $45^{\circ}$ angle), $0.75 \mathrm{~mL}$ from the top of the tube was aspirated and concentration adjusted to $10^{5}$ cells $/ \mathrm{mL}$ in TALP medium for insemination of the IVF dishes with $250 \mu \mathrm{L}$ of this suspension. Spermatozoa and oocytes were cocultured at $38.5{ }^{\circ} \mathrm{C}$ under $5 \% \mathrm{CO}_{2}$ in air saturated of humidity and $18 \mathrm{~h}$ post insemination (hpi); the putative zygotes were washed and transferred to embryo culture medium. For embryo culture, NCSU-23 media [47] supplemented with sodium lactate $(5 \mathrm{mM})$, pyruvate $(0.5$ $\mathrm{mM}$ ), non-essential amino acids and 0.4\% BSA-FAF (NCSU-23A, for the 18 to $48 \mathrm{hpi}$ ) or NCSU-23 supplemented with glucose $(5.5 \mathrm{mM})$, essential, non-essential amino acids and 0.4\% BSA-FAF (NCSU-23B, for 48-168 hpi) were used. At 48, 72, 120 and $168 \mathrm{hpi}$, pools of forty 2-4 cell embryos, twenty 8-16 cell embryos, ten morula and single expanded blastocyst were selected, washed in PBS and ZP digested by $0.5 \% \mathrm{w} / \mathrm{v}$ pronase in PBS. Finally, embryos were washed three times in PBS and snap frozen in liquid nitrogen until further processing.

\section{Ovum pick up for cow oocyte collection}

Non-lactating and non-pregnant cows $(n=3)$ located at the Farm Dairy facilities of the University of Murcia, Spain, were used as oocyte donors. Ultrasound evaluation was performed in order to assess the size of follicle(s) or to count the number of puncturable follicles. Ovum pick up was performed on $\geq 15 \mathrm{~mm}$ of diameter follicles. The system used for follicle aspiration was a Falco-Vet ultrasound with a $10 \mathrm{R}$ transvaginal probe at $7.5 \mathrm{MHz}$ (Esaote, Genova, Italy). Cows were given xylazine (Nerfasin', Fatro, Barcelona, Spain $-0.25 \mathrm{~mL} / 100 \mathrm{~kg}$ weight, IM), carprofen (Carprosan ${ }^{\circ}$, Fatro, Barcelona, Spain-1.4 mg/kg weight, SC) and lidocaine (Anesvet, Ovejero, León, Spain-2\%, $5 \mathrm{~mL}$, epidural). For oocyte retrieval, the aspiration pump (Aspirator 3-Labotect, Göttingen, Germany) applied a pressure of $70 \mathrm{~mm} \mathrm{Hg}$ and $20 \mathrm{~mL} / \mathrm{min}$, and the system included the punctionneedle (with a disposable $18 \mathrm{G}$ needle) connected via a sterile tube to a Falcon tube. The medium used to collect oocytes was Dulbecco's phosphate buffered saline, supplemented with $1 \%(\mathrm{v} / \mathrm{v})$ Fetal bovine serum and 2.2 $\mathrm{UI} / \mathrm{mL}$ heparin, pre-heated at $38^{\circ} \mathrm{C}$. After aspiration, oocytes were collected under a stereomicroscope (Nikon SMZ 10A, Japan) and washed twice in Dulbecco's phosphate buffered (without calcium or magnesium, PBS) supplemented with $0.5 \%$ polyvinyl alcohol (wt $/ \mathrm{v})$. Cumulus cells were removed with gentle pipetting, and vortex was used when necessary, as well as hyaluronidase $(0.2 \%$ in PBS). Zona pellucida was removed using pronase (0.5\% in PBS). Oocytes were put in $5 \mu \mathrm{L}$ of RLT buffer (Qiagen, Germany), immediately frozen in liquid nitrogen and stored at $-80^{\circ} \mathrm{C}$.

\section{IVM and IVF for collection of bovine embryo samples}

Immature cumulus-oocyte complexes (COCs) were obtained by aspirating follicles $(2-8 \mathrm{~mm})$ from the ovaries of matured heifers and cows collected at slaughter from local abattoirs. A total of 1425 COCs with homogenous cytoplasm and intact cumulus cells were matured in four-well dishes (Nunc, Roskilde, Denmark) in $500 \mu \mathrm{L}$ of TCM-199 maturation medium, supplemented with $10 \%$ (v/v) fetal calf serum (FCS) and $10 \mathrm{ng} / \mathrm{mL}$ epidermal growth factor (EGF) in 4 well dishes in groups of 50 COCs per well at $38.5{ }^{\circ} \mathrm{C}$ under an atmosphere of $5 \%$ $\mathrm{CO} 2$ in air with maximum humidity [55].

After $24 \mathrm{~h}$ of maturation, a representative number of the in vitro matured COCs were suspended in $100 \mu \mathrm{L}$ of PBS without calcium or magnesium supplemented with $1 \%$ BSA and their cumulus cells (CCs) completely removed by pipetting. Only oocytes presenting polar body were selected and snap frozen in pools of 100 in $\mathrm{LN}_{2}$ and stored at $-80{ }^{\circ} \mathrm{C}$ until use $(n=2)$.

The remaining matured oocytes were in vitro fertilized (IVF). IVF was performed as described previously [38]. Briefly, frozen semen straws from an Asturian Valley bull (ASEAVA, Asturias, Spain) previously tested for IVF were treated with Bovipure ${ }^{\mathrm{Tw}}$ (Nidacon, Sweden). Sperm concentration was determined and adjusted to a final concentration of $1 \times 10^{6}$ spermatozoa $/ \mathrm{mL}$. Gametes were co-incubated for $18-20 \mathrm{~h}$ in $500 \mathrm{~mL}$ fertilisation media (Tyrode's medium with $25 \mathrm{mM}$ bicarbonate, 22 $\mathrm{mM}$ sodium lactate, $1 \mathrm{mM}$ sodium pyruvate and $6 \mathrm{mg} /$ $\mathrm{mL}$ fatty acid-free BSA supplemented with $10 \mathrm{mg} / \mathrm{mL}$ heparin sodium salt; Calbiochem) in a four-well dish in groups of 50 COCs per well under an atmosphere of $5 \%$ $\mathrm{CO} 2$ in air, with maximum humidity at $38.5^{\circ} \mathrm{C}$.

After $18-20 \mathrm{~h}$ post-insemination (hpi), presumptive zygotes were denuded of cumulus cells by vortexing and then cultured in groups of 25 in $25 \mu \mathrm{L}$ droplets of synthetic oviductal fluid (SOF) [27] with $4.2 \mathrm{mM}$ sodium lactate, $0.73 \mathrm{mM}$ sodium pyruvate, $30 \mu \mathrm{L} / \mathrm{mL}$ BME amino acids, $10 \mu \mathrm{L} / \mathrm{mL}$ minimum essential medium (MEM) amino acids and $1 \mathrm{mg} / \mathrm{mL}$ phenol red, supplemented with $3 \mathrm{mg} / \mathrm{mL}$ BSA, under mineral oil at $38.5{ }^{\circ} \mathrm{C}$ under an atmosphere of $5 \% \mathrm{CO}_{2}, 5 \% \mathrm{O}_{2}$ and $90 \% \mathrm{~N}_{2}$ with maximum humidity.

At 33, 54, 132 and $168 \mathrm{hpi}$, pools of fifty 2 cell embryos, thirty 8 to 16 cell embryos, ten morulaes and individual blastocysts were selected respectively, vortexed in PBS for $3 \mathrm{~min}$ and were then treated with $0.5 \% \mathrm{w} / \mathrm{v}$ pronase in PBS to digest the zona pellucida. They were 
finally washed three times in PBS and snap frozen in $\mathrm{LN}_{2}$ and stored at $-80{ }^{\circ} \mathrm{C}$ until use $(n=2$ per embryo stage).

\section{RNA preparation and RNA-seq}

ARCTURUS ${ }^{\circ}$ PicoPure ${ }^{\bullet}$ RNA Isolation Kit (KIT0204, Life Technologies) was used to extract the RNA from oocytes, embryo pools or from individual blastocysts. RNA-seq libraries were generated using Ovation RNASeq System V2 (NuGEN, Cat. 7102-08) for low amount of starting material and further amplified with NEB Next DNA Library Prep Master Mix for Illumina for 8 PCR cycles (NEB, Cat. E6040S). All steps for RNA extraction and library preparation were performed according to manufacture guidelines. iPCRTag reverse primer with individual index was used to generate one biological replicate from each condition. One hundred base pairs single end reads were sequenced on Illumina HiSeq 1000, and sequencing data were bioinformatically processed.

\section{Transcriptome analysis}

Raw sequence reads were trimmed using Trim Galore to remove adapter contamination and reads with poor quality defined by low PHRED score. Data were mapped to assembly UMD3.1 (cow) or Sus scrofa 11.1 (pig); hisat algorithm was used to process the reads, and data were visualised with the Seqmonk software package (v.1.41; Babraham Institute). Only reads with high PHRED score were used in the analysis. Data were passed through an additional filter of having mapped quality score 20 or more before the processing.

Annotated mRNA features were quantitated as log2FPM (fragments per million reads of library) to obtain respective expression values.

Additionally, RNA seq data were used to look for alternative promoters; oocyte specific isoforms of Dnmt1 transcripts (Dnmt1o) were identified for both porcine and bovine embryos as well as oocyte specific TET2 transcript was detected in bovine embryos, and genomic regions $1500 \mathrm{bp}$ upstream and $500 \mathrm{bp}$ downstream of these alternative transcripts were used as promoters.

\section{DNA library preparation based on post-bisulfite adapter tagging}

An adaptation of whole genome bisulfite sequencing that involves post-bisulfite adapter tagging (PBAT) was used to analyse the methylome of germ cells and early embryos at single-base resolution on a genome-wide scale, as previously performed [6].

With the exception of bovine oocytes, at least two replicate PBAT libraries were generated from each stage, each comprising the equivalents of $\sim 80-150$ cells per sample. In the case of the blastocyst stage, libraries were generated from single whole blastocysts. For porcine oocytes, PBAT was conducted on metaphase-II (MII)stage oocytes obtained after in vitro maturation (IVM). Bovine oocytes were obtained by ovum pick-up after natural ovulation or hormonal stimulation and were processed for single-cell PBAT using the protocol described by [64] in this case, data from 28 individual oocyte libraries were merged for analysis.

For sperm methylome, bull and boar sperm DNA was extracted from ejaculates of two biological individuals. Cells were lysed in the lysis buffer containing 10\% SDS with proteinase $\mathrm{K}, 20 \mathrm{mM}$ Tris, $10 \mathrm{mM}$ DTT, $10 \mathrm{mM}$ EDTA, $150 \mathrm{mM} \mathrm{NaCl}$ and $10 \mathrm{mM} \mathrm{KCl}$ for $2 \mathrm{~h}$ at $50 \mathrm{C}$. Further, DNA was purified with phenol to chloroform at 1:1 ratio and precipitated with equal volume of isopropanol. DNA pellet was washed with $70 \%$ ethanol, air dried and dissolved in EB buffer. DNA concentration was measured using Nanodrop, and $10 \mathrm{ng}$ was used for bisulfite conversion and PBAT library preparation as described below. For other biological timepoints, pools of oocytes (100), 2 cell embryos (40), 8 cell embryos (30), morulae (10) or individual blastocysts were lysed for $1 \mathrm{~h}$ in $1 \%$ SDS with proteinase $\mathrm{K}$, and lysates were directly treated with bisulfite reagent using the Imprint DNA modification kit (Sigma, MOD50). DNA was eluted in EB buffer, and one round of first strand synthesis was performed using a biotinylated oligo 1 (5-[Btn] CTACAC GACGCTCTTCCGATCTNNNNNNNNN-3). Samples were further treated with Exonuclease I, washed and eluted in $10 \mathrm{mM}$ Tris- $\mathrm{Cl}$ and incubated with washed M280 Streptavidin Dynabeads (Life Technologies) to pull down the biotinilated fraction of DNA. Second strand synthesis was performed using oligo $2\left(5^{\prime}\right.$-TGCTGAACCG CTCTTCCGATCTNNNNNNNNN-3'), and samples were amplified for 12 PCR cycles using indexed iPCRTag reverse primer [50] with KAPA HiFiHotStart DNA Polymerase (KAPA Biosystems) and purified using $0.8 \times$ AgencourtAmpure XP beads (Beckman Coulter). Libraries were assessed for quality and quantity using highsensitivity DNA chips on the Agilent Bioanalyzer. Two biological replicates were generated for each of biological timepoint and prepared for $100 \mathrm{bp}$ single-end sequencing on Illumina HiSeq 1000 and sequenced at 4 samples per lane.

\section{Methylome analysis}

Library sequence reads were mapped to the pig (genomic assembly Sus scrofa 11.1) and cow (genomic assembly UMD 3.1) genomes using the Bismark software (v.0.19; Babraham Institute). DNA methylation analysis was done using the the SeqMonk software package (v.1.41; Babraham Institute).

For the unbiased analysis of studied genomes, 100 CpGs tiles were defined using CpG occurrences annotation track for each of the specie studied. Then, the 
bisulfite quantitation pipeline was run over existing tiles, 1 minimum count to include position and 5 minimum observations to include feature (100 CpGs tile). Only informative tiles were included in analysis, and tiles without data in all studied biological timepoints were removed. For this, the filter on values for individual tiles was applied, where values had to have value above 0 for exactly 6 of the 6 selected data stores, representing sperm, oocyte, $2-4$ cells, $8-16$ cells, morula and blastocyst timepoints.

To search for the molecular mechanisms regulating the methylation dynamics observed, the study analysed the methylation and expression status at specific families of genes involved in reprogramming. This was done using SeqMonk platform and running a targeted analysis against promoters of the genes using bisulfite methylation pipeline. Computational approach was used to define gene promoters as genomic regions of $1500 \mathrm{bp}$ upstream and $500 \mathrm{bp}$ downstream of transcriptional start sites. CpG coverage for promoters is supplied in Supplementary table 5. Methylation values were calculated in percentage of methylated CpGs/unmethylated CpGs per feature.

Additionally, targeted analysis of methylation and gene expression over various genomic features, including imprinted genes, was performed. First, specific annotations for the pig and cow species were built manually, looking for the locations of the genes showed at http:// www.geneimprint.com/ for each species at www.ncbi. nlm.nih.gov/gene. Second, their methylation (based on at least 10 methylation calls per feature) and gene expression values were obtained. Third, germline specific DMRs were searched: for this, $100 \mathrm{CpGs}$ tiles were used and filtered those with the methylation value above $75 \%$ methylation in either sperm or oocyte to obtain hypermethylated DMRs. Then, a second filter was applied to these DMRs to obtain only those that were specific to one of the germline only, i.e. methylation $>75 \%$ in oocytes and $<25 \%$ in sperm, and vice versa. For analysis of the DNA methylation dynamics of candidate imprinted genes, the clustering was performed using a PCA and the separation based on the first 2 components. Chisquare test was used to obtain the indicated $p$ values. Standard programmes in the R Studio were used in both cases.

For the targeted analysis of other genomic features such as CGIs (CpG islands), intergenic regions, hypoand hypermethylated oocyte domains (Hypo- and HyperDomains) filter of 1 count per position (CpG) and 10 observations (10 cytosines) per feature were used. For repetitive elements, 1 count per position and 5 observations per feature were selected. Methylation values were calculated as indicated above for reprogramming genes.
Finally, the possible correlation between the methylation values obtained at each stage and the gene expression values in the corresponding $\mathrm{CpGi}$ of the gene promoters was investigated. For this analysis, the steps described by Smith et al. in human [65] were followed. Briefly, the correlations were calculated with the statistical program R. For each graph, a table was generated with the expression and methylation values of the genes, where the rows will be the genes in question and the columns the different stages of development, both in methylation and expression. That table was used to calculate Pearson's correlation, and the plot was made with the ggcorrplot package. This analysis included the genes listed in the Supplementary Table 6.

\section{Supplementary information}

Supplementary information accompanies this paper at https://doi.org/10. 1186/s13148-020-00857-x.

\begin{abstract}
Additional file 1: Supplementary Table 1. Sequencing outputs for (a) PBAT or scBS-seq libraries from bovine samples; and (b) PBAT libraries from porcine samples. Supplementary Table 2. Sequencing output for RNA-seq libraries from porcine and bovine samples. Supplementary Table 3. $100-\mathrm{CpG}$ tiles losing or gaining methylation between the 2-4 and $8-6$ cell stages, filtering for tiles changing by $>10 \%$. Supplementary Table 4. Location of candidate gDMRs with respect to bovine imprinted genes identified by RNA-seq [9]. Supplementary Table 5. Promoter methylation and CPG coverage of DNMT, TET and related genes in pig and cow PBAT/scBS-seq datasets. Supplementary Table $\mathbf{6}$. Lists of pig and cow pluripotency and zygotic genome activation genes.
\end{abstract}

Additional file 2: Supplementary Figure 1. Principal Component Analysis (PCA) of replicate PBAT datasets from porcine and bovine gametes and preimplantation embryos, and merged scBS-seq datasets from bovine oocytes. Supplementary Figure 2. CpG coverage rates of merged PBAT or scBS-seq datasets from porcine and bovine gametes and preimplantation embryos. Supplementary Figure 3. The CpG methylation profiles from gametes to blastocyst in pig and cow; additional screenshots to accompany Figure $2 a$ and b. Supplementary Figure 4. Characteristics of regions gaining DNA methylation between the 2-4 and 8-16 cells stages: enrichment analysis for various genomic features; screenshots of representative regions. Supplementary Figure $\mathbf{5}$. Detection of DNMT1 transcripts originating from oocyte-specific or somatic promoters: screenshots of RNA-seq alignments and intron-spanning alignments. Supplementary Figure 6. Properties of genomic elements differentially methylated in oocytes and sperm in pig and cow. Supplementary Figure 7. Correlations between expression and promoter methylation for pluripotency and zygotic genome activation genes in gametes and preimplantation porcine embryos. Supplementary Figure 8. Correlations between expression and promoter methylation for pluripotency and zygotic genome activation genes in gametes and preimplantation bovine embryos.

\section{Abbreviations}

ART: Assisted reproductive technologies; BSA-FAF: Bovine serum albumin fatty acid free; CAMP: Cyclic adenosine monophosphate; CGIs: CpG islands; COCs: Cumulus cell-oocyte complexes; CpGi: CpG islands; DMR: Differentially methylated region; DNMT: DNA methyl transferase; DOHAD: Developmental origins of health and disease; EC: Embryo culture; eCG: Equine chorionic gonadotropin; EDTA: Ethylenediaminetetraacetic acid; EGF: Epidermal growth factor; FCS: Fetal calf serum; gDMR: Germline differentially methylated regions; H3K9me2/3: Histone 3 lysine 9 di- and tri-methylation; hCG: Human chorionic gonadotropin; hpi: Hours post-insemination; IVF: In vitro fertilisation; IVM: In vitro maturation; LINEs: Long interspersed nuclear elements; MEM: Minimum essential medium; MII: Metaphase-Il; PBAT: Postbisulfite adaptor tagging; PBS: Phosphate buffered saline; PCA: Principal 
component analysis; PVA: Polyvinyl alcohol; qRT-PCR: Quantitative real time polimerase chain reaction; RRBS: Representation bisulfite sequencing; scPBAT: Single cell post-bisulfite adaptor tagging; SDS: Sodium dodecyl sulphate; SINEs: Short interspersed nuclear elements; SOF: Synthetic oviductal fluid; TET: Ten-eleven translocation; ZFP: Zinc-finger protein; ZGA: Zygote genome activation

\section{Acknowledgements}

The authors are grateful to the El Pozo Alimentacion SA company (Murcia, Spain) for the generosity in providing ovaries in this study and the CEFU SA company (Murcia, Spain) for providing boar semen samples. We should like to thank Rocio Rivera and Li Yahan for providing coordinates of candidate bovine imprinted transcripts.

\section{Authors' contributions}

PC and GK designed the project; SC, RR, SG-M, DR, MS-C and J-LS contributed to embryo production and samples collection; El performed DNA extraction and library preparation; SA designed the bioinformatics and statistical analysis; SA, FK and FP-S contributed to the bioinformatics or statistical analysis; El, SC, GK and PC performed the analysis and interpretation of data; El, SC, GK and PC wrote the manuscript; all authors reviewed and approved the final version of the manuscript.

\section{Funding}

This work was funded by Fundación Seneca-Región de Murcia 20040/GERM/ 16, the European Union, Horizon 2020 Marie Sklodowska-Curie Action, REPBIOTECH 675526 and Biotechnology and Biological Sciences Research Council (BBS/E/B/000C0423).

\section{Availability of data and materials}

Data generated during this study are included in this published article, and its supplementary information files or available from the corresponding author on reasonable request.

\section{Ethics approval and consent to participate}

Collection of animal biological samples and experimental work related with ovum pick up in cows were performed under Institutional ethical approval of the Dirección General de Agricultura, Ganadería, Pesca y

Acuicultura-Región de Murcia, Spain Ref. n A13160609 and Ref. A13170706, respectively.

\section{Consent for publication}

Not applicable

\section{Competing interests}

The authors declare that they have no competing interests.

\section{Author details}

'Epigenetics Programme, The Babraham Institute, Cambridge CB22 3AT, UK. 2Physiology of Reproduction Group, Departamento de Fisiología, Universidad de Murcia, Campus Mare Nostrum, 30100 Murcia, Spain. ${ }^{3}$ Instituto Murciano de Investigación Biosanitaria, IMIB-Arrixaca-UMU, 30120 Murcia, Spain. ${ }^{4}$ Departamento Reproducción Animal, INIA, Madrid, Spain. ${ }^{5}$ Bioinformatics Group, The Babraham Institute, Cambridge CB22 3AT, UK. ${ }^{6}$ Centre for Trophoblast Research, University of Cambridge, Cambridge CB2 3EG, UK.

\section{Received: 7 November 2019 Accepted: 23 April 2020}

\section{Published online: 11 May 2020}

\section{References}

1. Barker DJ. The origins of the developmental origins theory. J Intern Med. 2007;261(5):412-7. https://doi.org/10.1111/j.1365-2796.2007.01809.x.

2. Beck S, Rhee C, Song J, Lee BK, LeBlanc L, Cannon L, et al. Implications of $\mathrm{CpG}$ islands on chromosomal architectures and modes of global gene regulation. Nucleic Acids Res. 2018;46(9):4382-91. https://doi.org/10.1093/ nar/gky147.

3. Bennett-Baker PE, Wilkowski J, Burke DT. Age-associated activation of epigenetically repressed genes in the mouse. Genetics. 2003;165(4):2055-62

4. Bourc'his D, Xu GL, Lin CS, Bollman B, Bestor TH. Dnmt3L and the establishment of maternal genomic imprints. Science. 2001;294(5551):25369. https://doi.org/10.1126/science.1065848.
5. Canovas S, Ivanova E, Romar R, Garcia-Martinez S, Soriano-Ubeda C, GarciaVazquez FA, et al. DNA methylation and gene expression changes derived from assisted reproductive technologies can be decreased by reproductive fluids. Elife. 2017a:6. https://doi.org/10.7554/eLife.23670.

6. Canovas S, Ivanova E, Romar R, García-Martínez S, Soriano-Úbeda C, GarcíaVázquez FA, et al. DNA methylation and gene expression changes derived from assisted reproductive technologies can be decreased by reproductive fluids. Elife. 2017b:6. https://doi.org/10.7554/eLife.23670.

7. Canovas S, Ross PJ, Kelsey G, Coy P. DNA methylation in embryo development: epigenetic impact of ART (assisted reproductive technologies). Bioessays. 2017c;39(11). https://doi.org/10.1002/bies.201700106.

8. Cao Z, Zhou N, Zhang Y, Wu R, Li Y, Li N. Dynamic reprogramming of 5hydroxymethylcytosine during early porcine embryogenesis. Theriogenology. 2014;81(3):496-508. https://doi.org/10.1016/j. theriogenology.2013.10.025.

9. Chen Z, Hagen DE, Elsik CG, Ji T, Morris CJ, Moon LE, et al. Characterization of global loss of imprinting in fetal overgrowth syndrome induced by assisted reproduction. Proc Natl Acad Sci U S A. 2015;112(15):4618-23. https://doi.org/10.1073/pnas.1422088112.

10. Cirio MC, Ratnam S, Ding F, Reinhart B, Navara C, Chaillet JR. Preimplantation expression of the somatic form of Dnmt1 suggests a role in the inheritance of genomic imprints. BMC Dev Biol. 2008;8:9. https://doi.org/ 10.1186/1471-213X-8-9.

11. Coy P, Lloyd R, Romar R, Satake N, Matas C, Gadea J, et al. Effects of porcine pre-ovulatory oviductal fluid on boar sperm function. Theriogenology. 2010; 74(4):632-42. https://doi.org/10.1016/j.theriogenology.2010.03.005.

12. Dean W, Santos F, Stojkovic M, Zakhartchenko V, Walter J, Wolf E, et al. Conservation of methylation reprogramming in mammalian development: aberrant reprogramming in cloned embryos. Proc Natl Acad Sci U S A. 2001;98(24):13734-8. https://doi.org/10.1073/pnas.241522698.

13. Deshmukh RS, Østrup O, Østrup E, Vejlsted M, Niemann H, Lucas-Hahn A, et al. DNA methylation in porcine preimplantation embryos developed in vivo and produced by in vitro fertilization, parthenogenetic activation and somatic cell nuclear transfer. Epigenetics. 2011;6(2):177-87.

14. Dobbs KB, Rodriguez M, Sudano MJ, Ortega MS, Hansen PJ. Dynamics of DNA methylation during early development of the preimplantation bovine embryo. PLoS One. 2013;8(6):e66230. https://doi.org/10.1371/journal.pone. 0066230 .

15. Duan JE, Jiang ZC, Alqahtani F, Mandoiu I, Dong H, Zheng X, Marjani SL, Chen J, Tian XC. Methylome Dynamics of Bovine Gametes and in vivo Early Embryos. Front Genet. 2019;10:512. https://doi.org/10.3389/fgene.2019. 00512.

16. Duffie R, Ajjan S, Greenberg MV, Zamudio N, Escamilla del Arenal M, Iranzo J, et al. The Gpr1/Zdbf2 locus provides new paradigms for transient and dynamic genomic imprinting in mammals. Genes Dev. 2014;28(5):463-78. https://doi.org/10.1101/gad.232058.113.

17. El Hajj N, Haaf T. Epigenetic disturbances in in vitro cultured gametes and embryos: implications for human assisted reproduction. Fertil Steril. 2013; 99(3):632-41. https://doi.org/10.1016/j.fertnstert.2012.12.044.

18. Fernandez-Gonzalez R, Moreira P, Bilbao A, Jimenez A, Perez-Crespo M, Ramirez MA, et al. Long-term effect of in vitro culture of mouse embryos with serum on mRNA expression of imprinting genes, development, and behavior. Proc Natl Acad Sci U S A. 2004;101(16):5880-5. https://doi.org/10. 1073/pnas.0308560101.

19. Funahashi H, Cantley TC, Day BN. Synchronization of meiosis in porcine oocytes by exposure to dibutyryl cyclic adenosine monophosphate improves developmental competence following in vitro fertilization. Biol Reprod. 1997;57(1):49-53.

20. Greenberg MV, Glaser J, Borsos M, Marjou FE, Walter M, Teissandier A, et al. Transient transcription in the early embryo sets an epigenetic state that programs postnatal growth. Nat Genet. 2017;49(1):110-8. https://doi.org/10. 1038/ng.3718.

21. Guo F, Li L, Li J, Wu X, Hu B, Zhu P, et al. Single-cell multi-omics sequencing of mouse early embryos and embryonic stem cells. Cell Res. 2017;27(8):96788. https://doi.org/10.1038/cr.2017.82.

22. Guo H, Zhu P, Yan L, Li R, Hu B, Lian Y, et al. The DNA methylation landscape of human early embryos. Nature. 2014;511(7511):606-10. https://doi.org/10.1038/nature13544.

23. Hanna CW, Penaherrera MS, Saadeh H, Andrews S, McFadden DE, Kelsey G, et al. Pervasive polymorphic imprinted methylation in the human placenta. Genome Res. 2016;26(6):756-67. https://doi.org/10.1101/gr.196139.115. 
24. Hayward BE, De Vos M, Judson H, Hodge D, Huntriss J, Picton HM, et al. Lack of involvement of known DNA methyltransferases in familial hydatidiform mole implies the involvement of other factors in establishment of imprinting in the human female germline. BMC Genet. 2003;4:2.

25. Hill PW, Amouroux R, Hajkova P. DNA demethylation, Tet proteins and 5hydroxymethylcytosine in epigenetic reprogramming: an emerging complex story. Genomics. 2014;104(5):324-33. https://doi.org/10.1016/j.ygeno.2014.08.012.

26. Hirasawa R, Chiba H, Kaneda M, Tajima S, Li E, Jaenisch R, et al. Maternal and zygotic Dnmt1 are necessary and sufficient for the maintenance of DNA methylation imprints during preimplantation development. Genes Dev. 2008;22(12):1607-16. https://doi.org/10.1101/gad.1667008.

27. Holm P, Booth PJ, Schmidt MH, Greve T, Callesen H. High bovine blastocyst development in a static in vitro production system using SOFaa medium supplemented with sodium citrate and myo-inositol with or without serumproteins. Theriogenology. 1999;52(4):683-700. https://doi.org/10.1016/S0093691X(99)00162-4.

28. Howell CY, Bestor TH, Ding F, Latham KE, Mertineit C, Trasler JM, et al. Genomic imprinting disrupted by a maternal effect mutation in the Dnmt1 gene. Cell. 2001;104(6):829-38.

29. Huan Y, Wang H, Wu Z, Zhang J, Liu Z, He H. The expression patterns of DNA methylation reprogramming related genes are associated with the developmental competence of cloned embryos after zygotic genome activation in pigs. Gene Expr Patterns. 2015;18(1-2):1-7. https://doi.org/10. 1016/j.gep.2015.04.001

30. lqbal K, Jin SG, Pfeifer GP, Szabó PE. Reprogramming of the paternal genome upon fertilization involves genome-wide oxidation of 5methylcytosine. Proc Natl Acad Sci U S A. 2011;108(9):3642-7. https://doi. org/10.1073/pnas.1014033108.

31. Jiang Z, Lin J, Dong H, Zheng X, Marjani SL, Duan J, et al. DNA methylomes of bovine gametes and in vivo produced preimplantation embryos. Biol Reprod. 2018. https://doi.org/10.1093/biolre/ioy138.

32. Kobayashi H, Sakurai T, Imai M, Takahashi N, Fukuda A, Yayoi O, et al. Contribution of intragenic DNA methylation in mouse gametic DNA methylomes to establish oocyte-specific heritable marks. PLoS Genet. 2012; 8(1):e1002440. https://doi.org/10.1371/journal.pgen.1002440.

33. Kurihara Y, Kawamura Y, Uchijima Y, Amamo T, Kobayashi H, Asano T, et al. Maintenance of genomic methylation patterns during preimplantation development requires the somatic form of DNA methyltransferase 1. Dev Biol. 2008;313(1):335-46. https://doi.org/10.1016/j.ydbio.2007.10.033.

34. Lane N, Dean W, Erhardt S, Hajkova P, Surani A, Walter J, et al. Resistance of IAPs to methylation reprogramming may provide a mechanism for epigenetic inheritance in the mouse. Genesis. 2003;35:6.

35. Lee K, Hamm J, Whitworth K, Spate L, Park KW, Murphy CN, et al. Dynamics of TET family expression in porcine preimplantation embryos is related to zygotic genome activation and required for the maintenance of NANOG. Dev Biol. 2014;386(1):86-95. https://doi.org/10.1016/j.ydbio.2013.11.024.

36. Li X, Ito M, Zhou F, Youngson N, Zuo X, Leder $P$, et al. A maternal-zygotic effect gene, Zfp57, maintains both maternal and paternal imprints. Dev Cell. 2008;15(4):547-57. https://doi.org/10.1016/j.devcel.2008.08.014.

37. Lodde V, Modina SC, Franciosi F, Zuccari E, Tessaro I, Luciano AM. Localization of DNA methyltransferase-1 during oocyte differentiation, in vitro maturation and early embryonic development in cow. Eur J Histochem. 2009;53(4):e24. https://doi.org/10.4081/ejh.2009.e24.

38. Lopera-Vasquez R, Hamdi M, Maillo V, Lloreda V, Coy P, Gutierrez-Adan A, et al. Effect of bovine oviductal fluid on development and quality of bovine embryos produced in vitro. Reprod Fertil Dev. 2015. https://doi.org/10.1071/ RD15238.

39. Mackay DJ, Callaway JL, Marks SM, White HE, Acerini CL, Boonen SE, et al. Hypomethylation of multiple imprinted loci in individuals with transient neonatal diabetes is associated with mutations in ZFP57. Nat Genet. 2008; 40(8):949-51. https://doi.org/10.1038/ng.187.

40. Mertineit C, Yoder JA, Taketo T, Laird DW, Trasler JM, Bestor TH. Sex-specific exons control DNA methyltransferase in mammalian germ cells. Development. 1998;125(5):889-97.

41. Messerschmidt DM, de Vries W, Ito M, Solter D, Ferguson-Smith A, Knowles BB. Trim28 is required for epigenetic stability during mouse oocyte to embryo transition. Science. 2012;335(6075):1499-502. https://doi.org/10. 1126/science.1216154.

42. Nakamura T, Liu YJ, Nakashima H, Umehara H, Inoue K, Matoba S, et al. PGC7 binds histone $\mathrm{H} 3 \mathrm{~K} 9 \mathrm{me} 2$ to protect against conversion of $5 \mathrm{mC}$ to $5 \mathrm{hmC}$ in early embryos. Nature. 2012;486(7403):415-9. https://doi.org/10.1038/nature11093.
43. O'Doherty AM, Magee DA, O'Shea LC, Forde N, Beltman ME, Mamo S, et al. DNA methylation dynamics at imprinted genes during bovine preimplantation embryo development. BMC Dev Biol. 2015;15:13. https://doi. org/10.1186/s12861-015-0060-2.

44. Okae H, Chiba H, Hiura H, Hamada H, Sato A, Utsunomiya T, et al. Genomewide analysis of DNA methylation dynamics during early human development. PLoS Genet. 2014;10(12):e1004868. https://doi.org/10.1371/ journal.pgen.1004868.

45. Ono R, Nakamura K, Inoue K, Naruse M, Usami T, Wakisaka-Saito N, et al. Deletion of Peg10, an imprinted gene acquired from a retrotransposon, causes early embryonic lethality. Nat Genet. 2006;38(1):101-6. https://doi. org/10.1038/ng1699.

46. Pagé-Larivière F, Sirard MA. Spatiotemporal expression of DNA demethylation enzymes and histone demethylases in bovine embryos. Cell Reprogram. 2014;16(1):40-53. https://doi.org/10.1089/cell.2013.0055.

47. Petters RM, Wells KD. Culture of pig embryos. J Reprod Fertil Suppl. 1993; 48(Journal Article):61-73.

48. Pitale PM, Howse W, Gorbatyuk M. Neuronatin protein in health and disease. J Cell Physiol. 2017;232(3):477-81. https://doi.org/10.1002/jcp.25498.

49. Proudhon C, Duffie R, Ajjan S, Cowley M, Iranzo J, Carbajosa G, et al. Protection against de novo methylation is instrumental in maintaining parent-of-origin methylation inherited from the gametes. Mol Cell. 2012; 47(6):909-20. https://doi.org/10.1016/j.molcel.2012.07.010.

50. Quail MA, Gu Y, Swerdlow H, Mayho M. Evaluation and optimisation of preparative semi-automated electrophoresis systems for Illumina library preparation. Electrophoresis. 2012;33(23):3521-8. https://doi.org/10.1002/ elps.201200128.

51. Quenneville S, Verde G, Corsinotti A, Kapopoulou A, Jakobsson J, Offner S, et al. In embryonic stem cells, ZFP57/KAP1 recognize a methylated hexanucleotide to affect chromatin and DNA methylation of imprinting control regions. Mol Cell. 2011;44(3):361-72. https://doi.org/10.1016/j.molcel. 2011.08.032

52. Rath D, Niemann $H$. In vitro fertilization of porcine oocytes with fresh and frozen-thawed ejaculated or frozen-thawed epididymal semen obtained from identical boars. Theriogenology. 1997;47(4):785-93.

53. Reik W, Walter J. Genomic imprinting: parental influence on the genome. Nat Rev Genet. 2001;2(1):21-32. https://doi.org/10.1038/35047554.

54. Richard N, Molin A, Coudray N, Rault-Guillaume P, Jüppner H, Kottler ML. Paternal GNAS mutations lead to severe intrauterine growth retardation (IUGR) and provide evidence for a role of XLas in fetal development. J Clin Endocrinol Metab. 2013;98(9):E1549-56. https://doi.org/10.1210/jc.2013-1667.

55. Rizos D, Lonergan P, Boland MP, Arroyo-Garcia R, Pintado B, de la Fuente J, et al. Analysis of differential messenger RNA expression between bovine blastocysts produced in different culture systems: implications for blastocyst quality. Biol Reprod. 2002;66(3):589-95.

56. Russell DF, Betts DH. Alternative splicing and expression analysis of bovine DNA methyltransferase 1. Dev Dyn. 2008;237(4):1051-9. https://doi.org/10. 1002/dvdy.21474.

57. Saenz-de-Juano MD, Ivanova E, Billooye K, Herta AC, Smitz J, Kelsey G, et al. Genome-wide assessment of DNA methylation in mouse oocytes reveals effects associated with in vitro growth, superovulation, and sexual maturity. Clin Epigenetics. 2019;11(1):197. https://doi.org/10.1186/s13148019-0794-y.

58. Sanchez-Delgado M, Court F, Vidal E, Medrano J, Monteagudo-Sanchez A, Martin-Trujillo A, et al. Human oocyte-derived methylation differences persist in the placenta revealing widespread transient imprinting. PLoS Genet. 2016;12(11):e1006427. https://doi.org/10.1371/journal.pgen.1006427.

59. Santos F, Hendrich B, Reik W, Dean W. Dynamic reprogramming of DNA methylation in the early mouse embryo. Dev Biol. 2002;241(1):172-82. https://doi.org/10.1006/dbio.2001.0501.

60. Schramm RD, Bavister BD. Onset of nucleolar and extranucleolar transcription and expression of fibrillarin in macaque embryos developing in vitro. Biol Reprod. 1999;60(3):721-8.

61. Schroeder DI, Jayashankar K, Douglas KC, Thirkill TL, York D, Dickinson PJ, et al. Early developmental and evolutionary origins of gene body DNA methylation patterns in mammalian placentas. PLoS Genet. 2015;11(8): e1005442. https://doi.org/10.1371/journal.pgen.1005442.

62. Shirane K, Toh H, Kobayashi H, Miura F, Chiba H, Ito T, et al. Mouse oocyte methylomes at base resolution reveal genome-wide accumulation of nonCpG methylation and role of DNA methyltransferases. PLoS Genet. 2013;9(4): e1003439. https://doi.org/10.1371/journal.pgen.1003439. 
63. Smallwood SA, Tomizawa S, Krueger F, Ruf N, Carli N, Segonds-Pichon A, et al. Dynamic CpG island methylation landscape in oocytes and preimplantation embryos. Nat Genet. 2011;43(8):811-4. https://doi.org/10. 1038/ng.864.

64. Smallwood SA, Lee HJ, Angermueller C, Krueger F, Saadeh H, Peat J, Andrews SR, Stegle O, Reik W, Kelsey G. Single-cell genome-wide bisulfite sequencing for assessing epigenetic heterogeneity. Nat Methods. 2014; 11(8):817-820. https://doi.org/10.1038/nmeth.3035.

65. Smith ZD, Chan MM, Humm KC, Karnik R, Mekhoubad S, Regev A, et al. DNA methylation dynamics of the human preimplantation embryo. Nature. 2014;511(7511):611-5. https://doi.org/10.1038/nature13581.

66. Smith ZD, Chan MM, Mikkelsen TS, Gu H, Gnirke A, Regev A, et al. A unique regulatory phase of DNA methylation in the early mammalian embryo. Nature. 2012:484(7394):339-44. https://doi.org/10.1038/nature10960.

67. Takahashi N, Coluccio A, Thorball CW, Planet E, Shi H, Offner S, et al. ZNF445 is a primary regulator of genomic imprinting. Genes Dev. 2019;33(1-2):4954. https://doi.org/10.1101/gad.320069.118.

68. Telford NA, Watson AJ, Schultz GA. Transition from maternal to embryonic control in early mammalian development: a comparison of several species. Mol Reprod Dev. 1990;26(1):90-100. https://doi.org/10.1002/mrd. 1080260113.

69. Tomizawa S, Kobayashi H, Watanabe T, Andrews S, Hata K, Kelsey G, et al. Dynamic stage-specific changes in imprinted differentially methylated regions during early mammalian development and prevalence of non-CpG methylation in oocytes. Development. 2011;138(5):811-20. https://doi.org/ 10.1242/dev.061416.

70. Uysal F, Akkoyunlu G, Ozturk S. Dynamic expression of DNA methyltransferases (DNMTs) in oocytes and early embryos. Biochimie. 2015; 116:103-13. https://doi.org/10.1016/j.biochi.2015.06.019.

71. Vassena R, Boué S, González-Roca E, Aran B, Auer H, Veiga A, et al. Waves of early transcriptional activation and pluripotency program initiation during human preimplantation development. Development. 2011;138(17):3699709. https://doi.org/10.1242/dev.064741

72. Veselovska L, Smallwood SA, Saadeh H, Stewart KR, Krueger F, MaupetitMehouas $S$, et al. Deep sequencing and de novo assembly of the mouse oocyte transcriptome define the contribution of transcription to the DNA methylation landscape. Genome Biol. 2015;16:209. https://doi.org/10.1186/ s13059-015-0769-z.

73. Wang X, Liu D, He D, Suo S, Xia X, He X, et al. Transcriptome analyses of rhesus monkey preimplantation embryos reveal a reduced capacity for DNA double-strand break repair in primate oocytes and early embryos. Genome Res. 2017;27(4):567-79. https://doi.org/10.1101/gr.198044.115.

74. White CR, Denomme MM, Tekpetey FR, Feyles V, Power SG, Mann MR. High frequency of imprinted methylation errors in human preimplantation embryos. Sci Rep. 2015;5:17311. https://doi.org/10.1038/srep17311.

75. Xue Z, Huang K, Cai C, Cai L, Jiang CY, Feng Y, et al. Genetic programs in human and mouse early embryos revealed by single-cell RNA sequencing. Nature. 2013;500(7464):593-7. https://doi.org/10.1038/nature12364.

76. Zhang Z, Cao Y, Zhai Y, Ma X, An X, Zhang S, et al. MicroRNA-29b regulates DNA methylation by targeting Dnmt3a/3b and Tet $1 / 2 / 3$ in porcine early embryo development. Develop Growth Differ. 2018;60(4):197-204. https:// doi.org/10.1111/dgd.12537.

77. Zhu P, Guo H, Ren Y, Hou Y, Dong J, Li R, et al. Single-cell DNA methylome sequencing of human preimplantation embryos. Nat Genet. 2018;50(1):12-9. https://doi.org/10.1038/s41588-017-0007-6

\section{Publisher's Note}

Springer Nature remains neutral with regard to jurisdictional claims in published maps and institutional affiliations.

Ready to submit your research? Choose BMC and benefit from:

- fast, convenient online submission

- thorough peer review by experienced researchers in your field

- rapid publication on acceptance

- support for research data, including large and complex data types

- gold Open Access which fosters wider collaboration and increased citations

- maximum visibility for your research: over $100 \mathrm{M}$ website views per year

At BMC, research is always in progress.

Learn more biomedcentral.com/submissions 